NIST Special Publication 2100-02

\title{
Notes from the NIST Research Innovation to Implementation in Forensic Science Symposium (RI2I) June 19-20, 2019
}

Richard R. Cavanagh, PhD NIST Special Programs Office

Aislinn Berge, MFS Amanda Coute, MFS Ron Fazio, MBA Timothy Graham, MFS Charla Marshall, PhD Jennifer Miller, MFS Lawrance Mullen, DHSc

Amanda Sozer, PhD Charlotte Word, PhD SNA International 
NIST Special Publication 2100-02

\section{Notes from the NIST Research Innovation to Implementation in Forensic Science Symposium (RI2I) June 19-20, 2019}

Richard R. Cavanagh, PhD NIST Special Programs Office

Aislinn Berge, MFS Amanda Coute, MFS

Ron Fazio, MBA Timothy Graham, MFS Charla Marshall, PhD Jennifer Miller, MFS Lawrance Mullen, DHSc

Amanda Sozer, PhD Charlotte Word, PhD SNA International

This publication is available free of charge from: https://doi.org/10.6028/NIST.SP.2100-02

November 2019

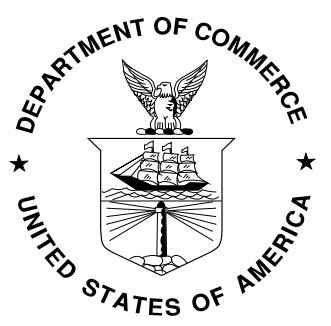

U.S. Department of Commerce Wilbur L. Ross, Jr., Secretary

National Institute of Standards and Technology Walter Copan, NIST Director and Undersecretary of Commerce for Standards and Technology 
Certain commercial entities, equipment, or materials may be identified in this document in order to describe an experimental procedure or concept adequately. Such identification is not intended to imply recommendation or endorsement by the National Institute of Standards and Technology, nor is it intended to imply that the entities, materials, or equipment are necessarily the best available for the purpose.

Publications in the SP 2100 subseries are proceedings from conferences organized predominately by NIST scientific and technical staff. These proceedings are published as a single document that includes all abstracts or extended abstracts accepted by the conference organizers. This publication may include external perspectives from industry, academia, government, and others. The opinions, recommendations, findings, and conclusions in this publication do not necessarily reflect the views or policies of NIST or the

United States Government.

National Institute of Standards and Technology Special Publication 2100-02 Natl. Inst. Stand. Technol. Spec. Publ. 2100-02, 59 pages (November 2019)

CODEN: NSPUE2

This publication is available free of charge from: https://doi.org/10.6028/NIST.SP.2100-02 
Proceedings of RI2I Symposium, NIST Gaithersburg, MD, June 19-20, NIST SP 2100-02

\section{Forward:}

The purpose of the symposium was to explore ways to ease the transition of innovations into the practice of forensic science. The concept for the symposium arose from discussions following the 2017 Symposium on Forensic Science Error Management. A steering committee helped with the design of the meeting, and included Jose Almirall (Florida International University), Arian van Asten (University of Amsterdam), John Butler (NIST), Richard Cavanagh (NIST), Ted Hunt (U.S. Department of Justice), Anil Jain (Michigan State University), Gerald LaPorte (National Institute of Justice), Barry Logan (NMS Labs), Willie E. May (NIST retired ${ }^{1}$ ), John Morgan (RTI International), Robert Morgan (National Institute of Forensic Science - Australia), Eugene Peters (FBI Laboratory), Karen Reczek (NIST), Mark Stolorow (NIST ${ }^{2}$ ), Robert Thompson (NIST), and Gillian Tully (UK Forensic Science Regulator).

The desire for an interactive meeting where different perspectives could be shared, and where ample opportunities for discussion and exchange would be provided for all participants led to the incorporation of SNA International for help with facilitation of the breakout sessions. The bulk of this summary report was prepared by the SNA authors listed in this NIST Special Publication.

Videos of the plenary sessions are available at https://www.nist.gov/newsevents/events/2019/06/forensic-science-research-innovation-implementation-symposiumri2i, as the visuals provided in Appendix D do not capture the comments of the speaker or the interactions with the audience.

The NIST Special Programs Office is interested in your feedback, both on the content of this Special Publication, and regarding future events that could help ease the path for moving innovations into practice in the forensic sciences. Please contact our office SPO@nist.gov.

Richard Cavanagh

Director, NIST Special Programs Office

\footnotetext{
${ }^{1}$ Currently Morgan State University

${ }^{2}$ Currently NIST- retired
} 
Proceedings of RI2I Symposium, NIST Gaithersburg, MD, June 19-20, NIST SP 2100-02

\section{Table of Contents}

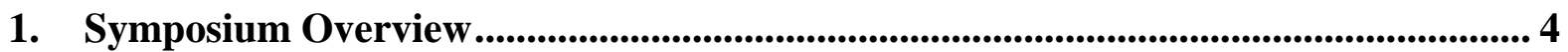

2. Plenary I: Research Perspective.............................................................................................. 4

Glen P. Jackson, Ph.D., Mingh Hsieh Distinguished Professor of Forensic and Investigative Science, West Virginia University - Innovation to Implementation: Research Perspective

Gene Peters, MS, Chief of Counterterrorism and Forensic Science Research at the FBI Laboratory - Challenges in Transitioning Research into Casework and Operations........... 5

3. Plenary II: Lab Management Perspectives .......................................................... 7

Jenifer Smith, Ph.D, Director, District of Columbia Department of Forensic Sciences (DFS) - Lab Management Perspective....

Edward Pollock, B.S, Laboratory Director of the Sacramento County District Attorney's Office Laboratory of Forensic Services - A Local Forensic Laboratory's Perspective on Implementing Cutting Edge Technology

4. Plenary III: Business Perspectives

Barry Logan, Ph.D., Chief Scientist at NMS Labs, Executive Director at the Center for Forensic Science Research and Education (CFSRE) at the Frederic Rieders Family Foundation - Business Perspectives - NMS Labs

Amy Liberty, MFS, J.D., Senior Product Manager with the Human Identification Division of Thermo Fisher Scientific - Innovation in Forensic Product Development

5. Plenary IV: Courts Perspectives

Stephanie Domitrovich, J.D., Judge Sixth Judicial District of Pennsylvania - Perils, Pitfalls and "Jeopardy" at the Intersection of Science and Law

Dawn Boswell, J.D., Chief Conviction Integrity Unit, Tarrant County Criminal District Attorney’s Office - Jeopardy....

6. Plenary V: Experience, Progress and Perspective from Abroad

Robert Morgan, Senior Forensic Project Officer at the National Institute of Forensic Science (NIFS) Australia New Zealand - Forensic Science Research and Innovation, Australia-New Zealand Perspective....

Gillian Tully, Ph.D. UK Forensic Science Regulator - UK Perspective...

7. Breakout Session A........................................................................................... 20

7.1. Research ................................................................................................................................... 20

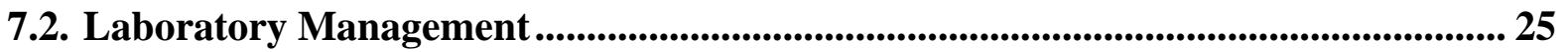

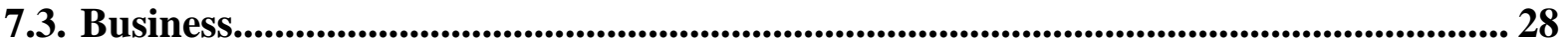

7.4. Legal...................................................................................................................................... 31

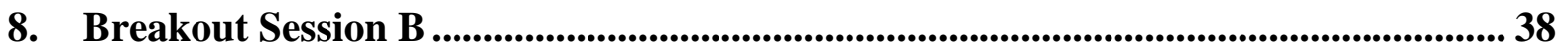

8.1. Group 1: Charla Marshall Facilitator ............................................................................... 38 
Proceedings of RI2I Symposium, NIST Gaithersburg, MD, June 19-20, NIST SP 2100-02

8.2. Group 2: Lawrance Mullen Facilitator .............................................................. 41

8.3. Group 3: Ron Fazio Facilitator ................................................................................. 43

8.4. Group 4: Charlotte Word Facilitator .............................................................................. 47

9. Summary of Breakout Sessions ....................................................................................... 49

9.1. Breakout Sessions A Summary .............................................................................. 49

9.2. Breakout Sessions B Summary .............................................................................. 52

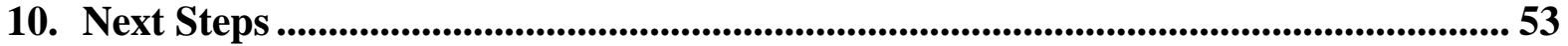

\section{Attachments}

Attachment A - Agenda

Attachment B - Attendee List

Attachment C - Plenary Session PowerPoints

Attachment D - Breakout A Summaries PowerPoint

Attachment E - Read-ahead Material 
Proceedings of RI2I Symposium, NIST Gaithersburg, MD, June 19-20, NIST SP 2100-02

\title{
1. Symposium Overview
}

Thousands of research papers are published in forensic science journals every year. Unfortunately, many of the innovations they describe never make it to the crime laboratory, where they could potentially provide forensic scientists with efficiencies and improved quality in operations. The National Institute of Standards and Technology (NIST) Research Innovation to Implementation in Forensic Science Symposium (RI2I) took place on the NIST campus June 19-20, 2019. The objective of the Symposium was to explore the challenges of transferring forensic science research into operations. During the two-day symposium, speakers and participants explored the barriers preventing new forensic technologies from being rapidly implemented and looked for ways to reduce the obstacles to successful innovation in our nation's crime laboratories. See Attachment A for the Symposium Agenda.

The symposium was attended by researchers, forensic science practitioners, and businesses and legal professionals, many of whom had experience in technology transfer. See Attachment B for a list of participants.

The Symposium began with welcoming remarks from Dr. Walter Copan, the Director of NIST, and Dr. Richard R. Cavanagh, the Director of the Special Programs Office. During five plenary sessions, speakers provided insight, experience, progress, and perspective on five topics:

\author{
I. Research \\ II. Laboratory Management \\ III. Business \\ IV. Legal \\ V. Abroad
}

Each afternoon, participants and speakers met in small groups for facilitated discussions. The following sections detail the topics covered by the speakers and the discussion groups. See Attachment $C$ for the speakers slides and Attachment D for the slides from the first day breakout group.

\section{Plenary I: Research Perspective}

\section{Glen P. Jackson, Ph.D., Mingh Hsieh Distinguished Professor of Forensic and Investigative Science, West Virginia University - Innovation to Implementation: Research Perspective}

Professor Jackson began his talk by discussing how new technology is implemented. First, there is fundamental research, then adaptation, validation, and, finally, implementation. Professor Jackson noted there is a wall between adaptation, validation, and implementation because of a lack of effective incentives for researchers to ensure their technology is 
Proceedings of RI2I Symposium, NIST Gaithersburg, MD, June 19-20, NIST SP 2100-02

implemented. Professor Jackson then explained Rogers' five stages of innovation adaptation: knowledge, persuasion, decision, implementation, and confirmation. Researchers and academics focus on the knowledge stage of adaptation.

When considering effective incentives for researchers, it is important to understand the needs of academics. Professor Jackson said academics take actions that will result in outcomes of increased status, respect, recognition, and importance. Academics are focused on activities that will help them obtain tenure, and implementing technologies in crime laboratories will not necessarily help them attain that goal. Academics prioritize grant money, publications, citations, presentations, recognition, teaching, and service. Academics need to ask themselves: how do the new technology developments fit in with my prioritized activities? There is a need for change in academia to provide more incentives for researchers to push their innovations further towards implementation.

Practitioners focus on the decision and implementation stages of adaptation. Practitioners' motivators are respect, importance, and societal value, and they prioritize the completion of casework and testimony over other aspects of their jobs, like maintenance of accreditation and certification, lab maintenance, and validation of new methods. Adopting a new technology requires validation, which is often their lowest priority.

Academia, industry, researchers, and the legal profession all have an interest in motivating change for practitioners, and the NIJ Forensic Technology Center of Excellence (FTCoE) helps bring it all together. The NIJ FTCoE's goals are to create new knowledge through research, and to then disseminate that knowledge.

Dr. Jackson described three "flavors" of incentives to help motivate change in forensic science: financial, social, and moral. Dr. Jackson discussed the pros and cons to the different types of incentives, including morale problems, scams/schemes, peer pressure, accountability, altruism, guilt, and the honor system.

Dr. Jackson then provided a case example of moving research into practice in which the state of Alabama decided to use portable Raman spectrometers with color spot reagents for on-site drug identifications. The implementation of these instruments saved \$2,000 per case and over $\$ 75,000$ per month. Dr. Jackson then discussed the barriers to widespread adoption, especially when a technology or solution has been shown to be so effective on a small scale.

The diffusion of innovation is shown as a graph of market saturation, where there is a “chasm" between early adopters of innovation and main majority adopters. Jackson described the importance of identifying the connectors, mavens, and persuaders (as described by Gladwell) in forensic science who can work cohesively to bring new technologies to the "tipping point” where they reach widespread adoption.

\section{Gene Peters, MS, Chief of Counterterrorism and Forensic Science Research at the FBI Laboratory - Challenges in Transitioning Research into Casework and Operations}

The FBI has a full-time research function, which focuses on the development of new capabilities, improvement of current methods, and improving the scientific foundation and 
defensibility of forensic science. Why isn't there more research? We would all agree that there are more challenges that exist in the forensics sciences than the number of people, time or money available. So how much research is going on today? Through government, universities, public-private, and private sector, there is research happening which leads to approximately 3500 to 5000 papers per year in over 250 journals. In addition to papers and presentations, sometimes this research also leads to products being developed. What makes research successful or complete? There is not currently a clear answer to this question.

The FBI Laboratory has a Research Review Team (RRT), which consists of six scientific leads, a research chief and casework representatives. This RRT is chartered to: evaluate priorities and casework needs; evaluate ideas, proposals, plans, and progress, and make go/no-go decisions; monitor research in progress; and evaluate progress and make close-out decisions. In addition to the RRT, the FBI has the Institutional Review Board (IRB) and the Laboratory Research Strategy and Gap Analysis group.

The FBI has dedicated research staff for strategic research, including principal investigators, visiting scientists, and casework staff. They also have dedicated laboratories totaling $2300 \mathrm{~m}^{2}$ (25,000 sq. ft.), complete with up-to-date technology. These laboratories cover a wide range of disciplines (chemical, trace elements, genetics, and microbiology). When needed, they are supplemented by external contract researchers.

How do we know when research is successful? Success means the delivery of: new/improved methods, devices, prototypes, or software; technical information; or scientific publications. However, success also requires adoption: changing business models; deployment of new methods, tools, etc.; and improved defensibility.

One of the biggest barriers to successful implementation is that innovation is risky. We have to be mindful of the technical, financial, and time risks that go with implementation, as well as the legalities around it. Who is responsible for these risks? Many don't want to take the chance. Innovation takes resources beyond research, but it is unclear who will provide those resources - the researcher or the customer/client.

There is the example of the Mitochondrial DNA - QPCR Assay: there were three versions. Each of the three control regions had different requirements. Then came the validation - 17 binders' worth!

Some potential solutions:

- Question-driven research vs. solution-driven research: what question are you trying to answer vs where can my solution be relevant?

- $\quad$ Requirement-driven research: defending the status quo vs. true innovation; assessing vulnerability

- Integrating casework representatives into the research team: this is a significant resource challenge

- $\quad$ Striving towards equipment parity: equipment sharing between research and casework - significant challenges remain 
Proceedings of RI2I Symposium, NIST Gaithersburg, MD, June 19-20, NIST SP 2100-02

- Deployment support through the full lifecycle of implementation: validation, training, and tech support

We have to keep in mind that forensic science is more than the criminal justice system. There are other forensic applications - are we leveraging lessons learned there? Regulatory practices and civil litigation have explicit recognition of the need to make decisions in the absence of complete information, and of uncertainty and variability.

\section{Plenary II: Lab Management Perspectives}

\section{Jenifer Smith, Ph.D., Director, District of Columbia Department of Forensic Sciences (DFS) - Lab Management Perspective}

Implementation used to be easier than it is today. In order for it to be successful, there needs to be synergy among government agencies, private companies, and academia. Research and innovation are required to address issues of accuracy, reliability, and validity in the forensic community. What are the questions that need answers for implementation to occur?

- What is the gap?

- Who are we doing this for?

- Is this an improvement or new/novel?

- Who has a "say" in final validation?

- Is anyone else doing this? $\rightarrow$ help from others can be beneficial

- What will the impact be on current operations?

- What will this cost? Who will be covering those costs?

- What is the time investment?

- What can I do to make this happen?

In 2009, the National Academy of Sciences (NAS) released its report, "Strengthening Forensic Science in the United States: A Path Forward,” in which it recommended the creation of a National Institute of Forensic Sciences (NIFS), which would fund peerreviewed research to address issues of accuracy, reliability, and validity in the forensic science disciplines.

There are a lot of ways the term validation is used - which is the 'correct' definition? Validation is a term that describes the various processes inherent in good scientific research and analysis. It has also been defined in the analytical context as the process of establishing, through documented experimentation, that a scientific method or technique is fit for its intended purpose. In layman's terms, validation is that the instrument does what it is intended to do.

John Butler's definition is probably the most well rounded one we have: Validation involves performing laboratory tests to verify that an instrument, software program, or measurement technique is working properly. These validation experiments typically examine precision, accuracy, and sensitivity, which all play a factor on the 3 R's of measurements: reliability, reproducibility, and robustness. 
There is no standardized implementation strategy that is generally accepted or utilized across forensic DNA laboratories for bringing a procedure (assay, instrument, or software) "on-line" in a forensic lab. However, across labs this typically includes the following steps:

- Installation of instrumentation or software and purchase of assay reagents

- Learning the technique and how to perform it properly

- Validation of the analytical procedure to define its range and reliability

- Creation of the standard operating procedures, with interpretation guidelines based on the validation studies

- Training of other personnel on the technique and

- Each trained analyst passing a qualification test for initial use in forensic casework.

After a procedure has been successfully implemented into use with forensic casework, proficiency tests are performed by qualified analysts on a regular basis to demonstrate successful application of the technique over time. These proficiency tests are done to meet ISO accreditation standards. ISO 17025 (General requirements for the competence of testing and calibration laboratories) is a standard concerning protocols and validation. Validation is the confirmation by examination and the documentation of objective evidence that the requirements for a specific intended use are fulfilled.

ISO 17025 goes on to state that laboratories shall validate non-standard methods, laboratorydesigned/developed methods, standard methods used outside their intended scope, and amplifications and modifications of standard methods to confirm that the methods are fit for the intended use. Validations shall be as extensive as necessary to meet the needs of the given application or field of application. Laboratories need to record the results, procedures, and a statement on whether the method is fit for its intended use. Furthermore, the range and accuracy of the values obtainable from validated methods, as assessed for the intended use, shall be relevant to the customer's needs.

Some other definitions of validation to keep in mind are developmental validation, preliminary validation, and internal validation.

A barrier that is sometimes seen for implementation is the admissibility of scientific evidence into the court. Admissibility hearings are held prior to trial in order to determine the validity of the "science" used to examine the evidence, as well as to determine whether an expert should be able to testify. These should not be reasons to deny the use of new technology. There are three phases representing validation to implementation. Phase I deals with training qualified examiners, developing competency tests, and obtaining certificates for calibration and standards. Phase II covers the distribution of competency tests, maintenance of proficiency, visits to other laboratories for best practices, and a draft validation. Phase III encompasses complete validation, drafts of Standard Operating Procedures (SOPs), training of qualified examiners in SOPs, and exploring research opportunities in partnerships with others within the scientific community.

There are many hurdles to implementation from a laboratory perspective, such as:

- Quality Assurance Guidelines and Standards 
Proceedings of RI2I Symposium, NIST Gaithersburg, MD, June 19-20, NIST SP 2100-02

- National DNA Index System Approval

- Scientific Working Group for DNA Analysis Methods (SWGDAM)

Validation Guidelines, DNA standards, FBI Notification to Congress, SWGDAM Interpretation Guidelines

- "Change weary" staff

- Internal validation studies

- Protocol creation

- Training

- Testing

- Procuring resources

Traditionally Next Generation Sequencing (NGS) has had a lengthy process for implementation. The Department of Forensic Science (DFS) has developed an approach which will hopefully shorten this process. The DFS NGS team consists of two experienced users with forensic backgrounds. They are joined by the DFS Technical Leader and two fulltime analysts with validation and casework experience. The first step to implementation is the developmental validation by the manufacturer. The second step is the internal validation by laboratories, where they identify advantages and limitations. The final step is postvalidation integration of the system into operational use. Here the training program and SOPs will be written, analysts will complete qualifications, proficiency testing can take place, and continued performance monitoring will occur. Many of the steps listed in step 3 can occur parallel with the internal validation work.

The goals for validation and implementation are: internal validation, SOPs and case documentation, documented training program, qualification, and go-live for casework.

\section{Edward Pollock, B.S, Laboratory Director of the Sacramento County District Attorney's Office Laboratory of Forensic Services - A Local Forensic Laboratory's Perspective on Implementing Cutting Edge Technology}

The Sacramento County Crime Laboratory provides service to approximately 1.5 million residents of over $2574 \mathrm{~km}^{2}$ (994 square miles). The laboratory employs 40 forensic scientists and is accredited under ISO/IEC 17025:2005 and ASCLD-LAB International 2011

Supplemental Requirements. It provides complete forensic science services, including crime scene response. In addition, the lab offers advanced trace evidence capabilities to local agencies and to agencies within and outside California.

In 2003, funding was approved for local laboratories and \$50 million was awarded to the Local Forensic Laboratory Improvement Program (LFLIP). The Sacramento County DA's Office Crime Lab applied for some of this funding to develop a Trace Evidence Resource Center (TERC). The goal of the TERC was to provide advanced trace evidence services to our local agencies, as well as to agencies throughout the state of California, and to establish a fee-for-service program for those services offered to agencies outside the local service area. They were awarded over \$3 million to perform laboratory renovation and purchase advanced evidence instrumentation. 
With a portion of those funds, the Sacramento County Crime Laboratory purchased a Laser Ablation - Inductively Coupled Plasma Mass Spectrometer (LA-ICP-MS). At the time, they were the only crime lab in the western part of the United States to offer this type of state-ofthe-art elemental analysis capability. The first case where the LA-ICP-MS was used was a double homicide in 2003, and results from the instrument were accepted into court in 2005. With this instrumentation, we also provided trace evidence services to agencies outside of Sacramento County.

With this implementation, the laboratory built a strong rapport with the instrument manufacturers. This relationship led to the manufacturers assisting with method development, providing improvement suggestions, and decreasing the gap between theoretical and practical aspects of examining forensic case samples.

The instrument also opened up opportunities for research. The NIJ sponsored funding for research in the elemental analysis of glass and led to the formation of the Elemental Analysis Working Group (EAWG). Sacramento County Crime Laboratory assisted with drafting the ASTM guideline for the Elemental Analysis of Glass by LA-ICP-MS. They were able to partner with NIJ-sponsored research on Glass Evidence Interpretation, and they strengthened the Evaluation and Interpretation of Glass Evidence Using Statistical Analysis of Collection Sets and Databases on Refractive Index and Elemental Data.

They were able to develop strong relationships with academia and worked on several forensic-related projects with Center for Advanced Research in Forensic Science at Florida International University in Miami, FL, as well as projects with the Department of Forensic and Investigative Science at West Virginia University. The implementation of this instrument also allowed for the development of a good reputation in the forensic science community.

Some of the lessons learned from the implementation process of this instrument:

- It is critical that management is on board with the endeavor

- Expect the unexpected

- It is important to build working relationships with the instrument manufacturer

○ Rely on their expertise to assist with method development

- Reach out to the forensic and scientific communities for assistance

- Provide training to investigators, attorneys, and the courts about the advantages and limitations of the cutting-edge technology

- Be prepared to handle the potential ramifications of having a new technology. For example, other labs will reach out and request services

- Take advantage of the research opportunities

- Bridge the gap between theoretical and practical aspects of the technology

- Take the opportunity to engage with local university forensic science programs

- Take advantage of database development opportunities

- Be patient and flexible with the process 


\section{Plenary III: Business Perspectives}

\section{Barry Logan, Ph.D., Chief Scientist at NMS Labs, Executive Director at the Center for Forensic Science Research and Education (CFSRE) at the Frederic Rieders Family Foundation - Business Perspectives - NMS Labs}

The NAS Report discusses the forensic science research needs that should encompass both research and practice. There is a lack of national strategy for forensic science research, and there are no universal priorities or guidelines. The NAS Report recommends a National Institute of Forensic Science (NIFS) to promote the development of forensic science into a mature field of multidisciplinary research and practice, which should be founded on the systematic collection and analysis of relevant data. In addition, the NAS Report recommends advancing quality and standards development through the NIFS in conjunction with government laboratories, universities, and private laboratories to develop tools for advancing forensic science.

How do we define "Research?” Research has many definitions, but the three that are applicable here are:

- Investigation or experimentation aimed at the discovery and interpretation of facts.

- Revision of accepted theories or laws in the light of new facts.

- Practical application of such new or revised theories or laws.

Some examples of forensic science research are the invention of new technology, the application of a new technology to solve a forensic problem, the adaptation of published methods to create a new capability or improve an existing test or process, the assessment of limitations and error rates in new or legacy technologies, and the identification of patterns and trends in forensic laboratory data.

Each stakeholder has vastly different end goals:

- Academia - basic research, not aligned with practitioner needs.

- Tech Companies - solutions looking for a problem.

- National Laboratories - targeted projects with funding, but how are projects prioritized?

- Government Practitioners - casework focus, research focus is to solve today's most pressing problem.

- Private Sector Forensics - innovation for differentiation to create a demand for its services.

Innovation is important to those in the private sector because it is how they attract new customers, how they compete to lower costs, and how they increase the quality of their products. The funding produced from innovation may be used for research and development, and therefore the private sector has to bear the financial burden of unsuccessful research and development. 
Proceedings of RI2I Symposium, NIST Gaithersburg, MD, June 19-20, NIST SP 2100-02

Private laboratories can only be successful at a scale where competing with "free" requires a compelling value proposition. What does innovation mean to private forensic science service providers?

- Identifying the need early and creating a solution

- Early adoption of technology to enable novel tests

- Rapid development and deployment of tests

- Messaging about availability and value of novel esoteric tests

- Awareness of time limited opportunities

In private sector forensics, fortune favors the prepared mind and forward thinking benefits these laboratories. Private laboratories need to vet opportunities and rank projects based on: forensic application, academic/messaging potential, track record, meets a need, technology assessment, and cost analysis and revenue potential. This is all reviewed by a research and development governance/investment council. Companies generally put projects into one of four categories:

- Bread and butter

- Pearl in oyster

- Oyster

- White elephant

Possible outcomes from the NMS Labs’ Research \& Development Governance/Investment Council are: Approval, Denial (no further action), and Special Request/Forensic Investigation. When a project is denied, can a non-profit organization (NPO) pick it up? The Center for Forensic Science Research and Education (CFSRE) is NMS Labs’ 501(3)c corporation for non-profit research. The CFSREs mission is to improve the best practices of forensic science and promote the field's advancement by providing leadership, performing relevant research, and providing high-quality education and training programs for students, practitioners, and the law enforcement and legal communities.

Public-private partnerships/outsourcing esoteric testing create demand that encourages innovation by private providers. Key private sector research and innovation targets are: emerging needs, esoteric tests that address consolidated demand, technology specific opportunities, and brand development.

\section{Amy Liberty, MFS, J.D., Senior Product Manager with the Human Identification Division of Thermo Fisher Scientific - Innovation in Forensic Product Development}

Thermo Fisher has 70,000 employees, with over 5000 Research and Development (R\&D) scientists and engineers. Thermo Fisher invests \$1 billion annually in R\&D, with over \$24 billion in annual revenue.

Where does product development innovation start? First, we need a clear understanding of customer needs, and we need access to an array of technologies to address those customer problems. Finally, product development begins with new ideas. Some expected outcomes of innovation are: robust products built with the consumer in mind, increased efficiency, and 
Proceedings of RI2I Symposium, NIST Gaithersburg, MD, June 19-20, NIST SP 2100-02

consistent results. Project Innovation Areas cover product design, product differentiation, project compatibility, and service and support.

The importance of quantification on the DNA Analysis Workflow is four-fold:

- Assesses success of DNA extraction

- Determines the quantity of human (and human male) DNA for downstream amplification

- Provides information regarding the quality of the DNA samples for downstream analysis

- Allows for proper selection of downstream analysis tests, conserving precious samples

Some of the quantification product innovations from Thermo Fisher have been the Quantiblot Kit to the Quantifiler Trio/HP Kits, validation services, Y Screen Protocol, QuantStudio 5, HID Real-Time SW v1.3.

The Production Cycle is not linear but cyclical, with each previous step feeding into the next. First is Product Design, where the need for an innovation is identified. There was a need for innovation from the Quantiblot due to its limitations of being too time consuming (2.5 hour), 40 samples at a time, a subjective manual interpretation process, and limited sensitivity of detection (300 pg to $600 \mathrm{pg}$ ). The Real-Time Assay provided decreased procedure time (15 to 20 minutes), higher throughput (80 samples at a time), automated quantitative interpretation, increased sensitivity (23 pg), and it utilizes the TaqMan Technology while multiplexing capability.

Innovation input from consumers is integral to Thermo Fisher's success in creating products that will be used by customers. The Voice of the Customer (VOC) feedback is gathered from interactions with the teams (sales, support, marketing, product management, FSAG, etc.), customer presentations and publications, recommendations from Scientific Advisory bodies (Scientific Working Group on DNA Analysis Methods (SWGDAM), National DNA Index System (NDISD, European Network of Forensic Science Institutes (ENFSI), etc.), site visits and interviews, and customer surveys.

How do we translate these voices and feedback into requirements? After site visits, a core team spends a significant amount of time in a think tank analyzing and synthesizing all of VOC, and then brainstorms on how to best solve the problems presented.

Product development is the second step of the cycle and mostly focuses on R\&D. However, there are three other aspects involved: Product Management, Manufacturing, and Project Management. All three of these groups work closely with R\&D to pull a product together. During this step, the innovation progresses through the Product Commercialization Process (PCP), where it must be tested extensively at each checkpoint to confirm it is meeting specifications and expectations. 
Proceedings of RI2I Symposium, NIST Gaithersburg, MD, June 19-20, NIST SP 2100-02

The third step is Product Transfer, which is where Technology Transfer has to take things out of the "R\&D Kitchen" and bring them into a large-scale manufacturing environment without losing quality. Technology Transfer is responsible for managing raw material supply, infrastructure, storage conditions and shelf life, manufacturing and product documentation, manufacturing team training, and transfer support to product assurance.

Manufacturing is the fourth step, and UK Manufacturing has had ISO 13485 in place since 2010 and have been compliant to ISO 9001 since 1998. In this facility the primary focus is in the reduction of human DNA contamination, which led to automation starting in 2009. In addition to automation, the facility has been upgraded with manufacturing clean rooms, and a validated cleaning process was adopted.

The final step is Product Support. Thermo Fisher has multi-level support through Forensic Science Applications, Field Sales, Service and Support, Product Assurance, and Human Identification Division (HID) Professional Services. All of these teams work together to provide comprehensive support across all of the AB components of workflow, including instruments, software, and reagents.

Some of the customer needs, combined with a limited number of staff and a high workload, can overwhelm operations, so the HID Professional Services (HPS) serves as a direct line between customers and the manufacturers. HPS has expeditious and thorough validation solutions, decades of experience in the forensic community, and provides continued assistance after completion of validation. The HPS works very closely with customers to make sure they are operating efficiently. The HPS services over 500 projects in the US, with an additional $200+$ projects internationally.

Thermo Fisher recognizes that prevention is better than a cure when it comes to quality issues, which is why they invest so much in preventing inconsistencies or other issues with products.

\section{Plenary IV: Courts Perspectives}

\section{Stephanie Domitrovich, J.D., Judge Sixth Judicial District of Pennsylvania - Perils, Pitfalls and "Jeopardy" at the Intersection of Science and Law}

Procedural Rules (Motion in Limine): is the witness qualified as an expert? Is testimony reliable? The burden of proof shifts to the proponent of evidence or an expert. The two relevant cases to this are Frye v. U.S., 293 F 1013 (D.C. Cir 1923) and Daubert v. Merrell Dow. Pharm., 509 U.S. 579 (1993).

The Frye Test is a one-page decision that was used in Federal courts from 1923 through1993. It is still used in several states presently. With the Frye Test, we need "general acceptance" in the relevant scientific community.

"Just when does scientific principle or discovery cross the line between experimental and demonstrable stages is difficult to define. Somewhere in this twilight zone, evidential force of principle must be recognized, and while courts will go a long way 
Proceedings of RI2I Symposium, NIST Gaithersburg, MD, June 19-20, NIST SP 2100-02

in admitting expert testimony deduced from well-recognized scientific principle or discovery, the thing from which the deduction is made must be sufficiently established to have gained general acceptance in the particular field in which it belongs."

The newer Daubert Test has been used both federally and in many state courts since 1993. The Daubert test is a non-exclusive list of questions for "gatekeepers:"

- Has the theory or technique been tested?

- Has it been subjected to peer review and publication?

- Is there a known or potential rate of error in the technique?

- Is it generally accepted in the relevant scientific community? (Frye)

- Do standards exist for controlling the technique's operation and are those standards maintained?

Case example: G.E. v. Joiner, 522 U.S. 136 (1997)

- Fitting "facts" to be relevant and reliable

- Trial court has sole discretion to admit or reject proposed "scientific" evidence

- Standard on appeal is an abuse of discretion: where a trial court must exercise discretion in deciding a question, it must do so in a way that is not clearly against logic and the evidence. An improvident exercise of discretion is an error of law.

Case example: Kumho Tire Co. v. Carmichael, 526 U.S. 137 (1999)

- Clarified that Daubert factors may apply to non-scientific testimony "meaning testimony of engineers and other experts who are not scientists."

- Under FRE 702, no relevant distinction made between "scientific" knowledge and “technical” or "other specialized” knowledge

Under Pennsylvania law, in the Grady vs Frito-Lay case of 2003, Frye is considered a proven and workable rule, which when faithfully followed, assists trial courts in determining when scientific evidence is reliable and should be admitted. With the complexity of science, Frye state jurisdictions believe it is best to require judges to pay deference to the experts who are in the best position to evaluate the merits of scientific theory and techniques when ruling on admissibility of scientific proof. Frye jurisdictions believe Frye is a better way of ensuring that only reliable expert scientific evidence is admitted at trial and yields uniform, objective, and predictable results among courts than is the application of the Daubert standard, which balances factors.

Decisions of individual judges, whose backgrounds in science may vary widely, will be similarly guided by consensus in the scientific community. Wisdom and efficacy in Frye's "general acceptance" rules and continues to control in Frye states such as Pennsylvania.

The U.S. Supreme Court holds that it is the responsibility of the jury - not court-to decide what conclusions should be drawn from evidence admitted at trial. Reviewing court may set 
Proceedings of RI2I Symposium, NIST Gaithersburg, MD, June 19-20, NIST SP 2100-02

aside the jury's verdict on grounds of insufficient evidence only if no rational trier of fact could have agreed with the jury.

Federal court may not overturn a state court decision simply because federal court disagrees with state court. Federal court instead may do so only if the state court's decision was “objectively unreasonable."

Because rational people can sometimes disagree, an inevitable consequence of this settled law is that judges will sometimes encounter convictions they believe to be mistaken but that they must nonetheless uphold. This was illustrated by an example involving shaken baby syndrome where the Court of Appeals substituted its judgment for that $\mathrm{o}$ : $\mathrm{f}$ a California jury on the question of whether the prosecution's or the defense's expert witnesses more persuasively explained cause of a death. Judgment of the Court of Appeals was reversed.

Under FRE 706, the court has authority to appoint its own experts. On its own motion or on motion of either party, the court may enter Rule to Show Cause as to why expert witnesses should not be appointed. The court may request parties to submit nominations of expert witnesses. The court must have consent of the expert before the court appoints them. The court shall inform the expert of their duties. Those experts can be deposed and crossexamined. Some advantages to 706 appointments are:

- Aids in decision-making

- Enables confidence-building and tutoring of the judge

- Provides effectiveness in complex cases

- Increases science quotient of the judge

- May aid in reaching a settlement

- Provides basis for identifying disagreement between privately retained experts

- Narrows the issues

- Keeps privately retained experts “honest” by mere presence in courtroom

\section{Dawn Boswell, J.D., Chief Conviction Integrity Unit, Tarrant County Criminal District Attorney's Office - Jeopardy}

This presentation was done very differently: we played a round of the game Jeopardy and both Dawn Boswell and Stephanie Domitrovich discussed various aspects of the court. The five categories of Jeopardy questions: We Don’t Love Science, That Songs Slaps, Court Room Life, Admit It, and If It Ain't Broke. The issues that emerged from playing the game included:

- To the courts, risk is bad. What is at stake?

- The language of the courts does not always equal the language of science. Court personnel (judges, lawyers, jury) cannot be experts in all disciplines presented in court.

- Courts cannot do scientific research outside of the courtroom as it pertains to a case. This is because all knowledge about a technique, etc. needs to be on the record. 
Proceedings of RI2I Symposium, NIST Gaithersburg, MD, June 19-20, NIST SP 2100-02

\section{Plenary V: Experience, Progress and Perspective from Abroad}

\section{Robert Morgan, Senior Forensic Project Officer at the National Institute of Forensic Science (NIFS) Australia New Zealand - Forensic Science Research and Innovation, Australia-New Zealand Perspective}

Forensic Science Service Provision in Australia and New Zealand is spread across Police, Health, and Justice departments in each of the six states and two territories in Australia, as well as New Zealand. They cover common law jurisdictions and uniform evidence law jurisdictions. Australia does not have specific reliability requirements equivalent to Frye or Daubert but does have expert evidence requirements as well as mechanisms to assess new methodology or techniques that are either led by the Judge or Defense: Voir Dire, Basha Hearing. The expertise of the witness is often the area of focus if forensic science results are being challenged.

In Australia National Institute of Forensic Science (NIFS) promotes and facilitates excellence in Forensic Science through coordination, education and training, quality, information management, and innovation. In the area of innovation, the research and innovation program focuses on identifying agreed research priorities, opportunities for collaboration, and opportunities to drive implementation.

Research and implementation roadblocks in Australia and New Zealand are the same as those faced since 2001, when the Crimes Amendment (Forensic Procedures Act) was established. These are limited funding, insufficient time and research expertise, ineffective research culture, lack of strategic approach, and difficulties in operationalizing research outcomes.

NIFS regularly receives requests to support a research initiative. Often it is a difficult balancing act between the limited funds and competing priorities. Due to these issues, NIFS has developed a Research and Innovation Roadmap and Strategy. The path from innovation to implementation is not always a straight line, and not all research projects follow that pathway the same way. First there is creation, the blue-sky development of new methods and technology. Second is Adaptation/Extension, where you take methods/technology from other industries and develop them for a forensic science application. Finally, there is adoption, which is where validation and verification of new forensic science techniques and instrumentation are done.

The Roadmap was developed with consideration of the broader context of law enforcement. There was a need to highlight the importance of fundamentals and innovation identifying new forensic science opportunities, as well as an operational need. The ultimate goal is crime disruption, prevention, and resolution. To accomplish this, feedback and input was sought from service providers, researchers, and technology providers. After reviewing feedback from the community, we were able to identify high-level priorities for the coming years, grouped by forensic response. In addition, these were aligned with policing priorities, and the Australia New Zealand Policing Advisory Agency (ANZPAA) Board priorities (Police Commissioners). 
We also develop an annual priority project list posed as questions for researchers to use their expertise to identify novel ways of addressing those problems. The Specialist Advisory Group (SAG) Network consists of discipline-based groups that identify required research, while the Forensic Fundamental Working Groups (FFWGs) also identify research priorities through gap analysis projects. Both of these inputs are reviewed by the Research and Innovation Advisory Committee (RIAC) to develop the annual projects.

NIFS' strategy is to provide financial and in-kind support where possible, present and encourage opportunities to leverage resources, collaborate, and increase implementation. Increasing implementation can be done by driving research and innovation initiatives towards service provider requirements, reporting on project outcomes, and promoting the benefits of research outcomes.

Feedback from the Australia-New Zealand Community focused on engaging researchers and practitioners from start to finish, considering the operational outcomes and the balance of cost vs. benefit, and the use of samples representative of casework, robust methodology and analysis. This feedback also led to the following questions:

Morgan posed some of the questions and answers that emerged from the community, such as:

What is the best pathway to ensure the successful implementation of research outcomes in an operational setting?

- Promote work at meetings/workshops/conferences

- Include implementation/validation/resourcing considerations in the research output

- Create research infrastructure within operational laboratories

- Keep a staged approach with operational goals in mind

Do you consider the operational usage of research outcomes when identifying research topics/structuring a research project? Why?

- Balance of addressing an operational problem vs. demonstrating intellectual contribution/novelty

- Contractual obligation to meet operational outcomes where funding is provided

- Some research is driven by fascination and funding instead of feasibility

When considering operational usage, do you look to short term (1 to 2 years) or long term (5 to 10 years) goals of the operational setting? Why?

- Both are required.

○ Short-term to address current issues (adoption, adaptation/extension)

○ Long-term to look to future developments (blue sky)

What portion of research outcomes have been implemented in an operational setting for research projects that you have been involved in? Why?

- Survey identified most people don’t think about this point 
Proceedings of RI2I Symposium, NIST Gaithersburg, MD, June 19-20, NIST SP 2100-02

$\circ$ not considered at the beginning

- not part of an application process

○ not usually measured

- Generally, 'implemented' is considered to mean some operational impact.

○ Researchers in operational settings up to 70\% (adoption, adaptation/extension)

$\circ$ Researchers in academic settings up to 30\% (blue sky)

Who owns the translation role, researchers or service providers?

- It is likely a mix of both parties, an issue that is not exclusive to the forensic science community.

- Some researchers focus on meeting academic standards.

o Their outcomes need to be translated for operational purposes.

- Meanwhile, some service providers do not have the time and resources to perform this role in its entirety.

o They believe that researchers should work towards delivery of a fit-forpurpose product.

Recently, Australian universities are placing greater emphasis on industry partnerships, where the role for NIFS is in collaboration.

\section{Gillian Tully, Ph.D. UK Forensic Science Regulator - UK Perspective}

The role of the Regulator is an independent role and the job function is to ensure that provision of forensic science services across the Criminal Justice System is subject to an appropriate regime of scientific quality standards.

Crime is not static, it keeps changing, so science needs to keep up! Section 3.3 Research Priorities from a Quality Perspective in the Forensic Science Regulator's Annual Report 2018 prioritizes research to underpin the scientific basis of methods such as facial comparison, where research is limited. Research priorities from a quality perspective include provision of data and robust interpretation methods to support the effective evaluation of evidential significance. For example, the structured studies on the transfer and persistence of trace evidence and the significant factors affecting such transfer. Research supports quality, which can be defined by balance, logic, robustness, and transparency.

Forensic Science Regulator's (FSR) Codes of Practice and Conduct include a statement of standards and accreditation requirements. The Codes of Practice explain and expand on requirements of ISO 17025 (General requirements for the competence of testing and calibration laboratories) and 17020 (Conformity assessment - Requirements for the operation of various types of bodies performing inspection).

In 2005, the House of Commons Science and Technology Committee reported that "the absence of an agreed upon protocol for the validation of scientific techniques prior to their being admitted in court is entirely unsatisfactory. Judges are not well placed to determine 
Proceedings of RI2I Symposium, NIST Gaithersburg, MD, June 19-20, NIST SP 2100-02

scientific validity without input from scientists.” The codes are therefore prescriptive on the process for validation. They should be designed to manage risk, to avoid unfocused testing, and to promote the identification of limitations.

Requirements for validation differ depending on the user's purpose. Validation plans need to be structured around risks, and acceptance criteria set before testing starts. Assessment of the validation report needs to be done by someone independent of the validation or research team.

An implementation plan also needs to be written. This plan takes into consideration visitation of old cases, SOPs, training and competence assessments, integration with other methods, and ongoing control of the methods.

Progression needs collaboration. The fundamental science and research community needs to be aware of the end user's needs and the quality standards. Procurement drives collaboration when the user gives clear specification of requirements, including requirements for ongoing testing. This feeds into the provider's delivery to specification, testing to user requirement, and sharing of test data.

Some common pitfalls for failure to implement new technology are that it's a lengthy time requirement and labs are "too busy" to improve. Accreditation is sometimes thought to be a barrier to implementation but in fact it can be helpful, in that there is a baseline from which improvements can be measured. However, there is a cost to extending the scope of accreditation for new methods.

The following observations have been made from previous implementation attempts, and these should be avoided for successful implementation:

- Jumping too soon into validation

- Unfocused testing

- Not completing the write-up

- Poor archival of validation results

- Failure to communicate

- Inability to demonstrate what exactly is being tested

\section{Breakout Session A}

The participants were assigned by NIST to one of four different focus groups: Research, Laboratory Management, Business and Legal. The participants were asked to expand on the topics discussed during the Plenary lectures.

\subsection{Research}

Scientific innovation can strengthen the value of forensic casework, thereby having a direct impact on the medico-legal and criminal justice systems. Novel technologies may offer new capabilities, enhanced sensitivity, and rapid detection, producing more accurate results in a 
shorter time frame. Some examples of recent advancements in forensic science include Rapid DNA, Next-Generation Sequencing, probabilistic genotyping, genetic genealogy, and liquid chromatography - quadrupole time-of-flight mass spectrometry (LC-QTOF-MS), among others. Forensic science research is conducted at large state and federal laboratories, universities, research institutions, as well as private and nonprofit companies. Many smaller laboratories may not have the resources or personnel to devote to research and development, relying on external sources to guide the direction of technological advancement. Funding for forensic science research may come from internal sources, state governments, federal agencies such as the National Institute of Justice (NIJ), or private entities. Once research projects are completed, the primary outcomes are disseminated in the form of commercial products, scientific papers, and patented technologies. However, most research outcomes may never be implemented in forensic science laboratories. The reasons are many-fold, including scientific conservatism of the legal system, limited funding and resources, and restrictive quality systems.

This breakout session was aimed at discussing the implementation hurdles from a scientific researcher's perspective. The group was composed of approximately 30 researchers, primarily from NIST. Other affiliations included the FBI Laboratory, various universities (Florida International University, Sam Houston State University, Iowa State University, West Virginia University, Boston University), and a private consultant. Several questions were posed to the group in order to provoke thoughtful discussion around the barriers and possible solutions to the implementation of research outcomes in forensic science.

What is Research? The group explored whether research just encompasses "traditional" research and development or if it also includes validation. The group felt research included developing new techniques and new knowledge that results in journal publications and research documents. Research champions are those who sell ideas and technology via presentations and demonstrations. And research can be assessed through technical/translational readiness level (TRL) TRL 1 -TRL 4.

Key Points:

- The commercialization of research is very important in getting new techniques operational in a laboratory.

- Method enhancements are also considered research. Some large laboratories have their own research departments that focus solely on new and improved method development for their laboratory operations.

- NIST employees can provide support in validations and evaluations. However, they felt limited because they are not allowed to make recommendations for commercial products that could potentially be helpful to the forensic community.

- Technology developed by teams tends to be more successful than technology developed by an individual.

- Many researchers are driven by the need to publish papers in peer-reviewed journals. Once a paper is published, there may be little incentive to commercialize the research it describes. 
Proceedings of RI2I Symposium, NIST Gaithersburg, MD, June 19-20, NIST SP 2100-02

- Researchers can obtain patents but implementing a patent idea into a commercial product that will be helpful to the end user takes resources (time and money) most academics do not have access to.

Aversion to using new techniques: Forensic laboratories are often risk-averse and take a very conservative approach to implementing new technologies. This is because small changes in forensic laboratory operations can have large consequences. For example, a small change in a laboratory procedure may require validation studies and changes to written standard operating procedures. Therefore, laboratory managers take comfort in the status quo and are resistant to change.

Key Points:

- Transition champions are needed to move new techniques from research to casework. The FBI research section is an example of a model of casework collaboration.

- Having forensic end users involved in research has shown to produce successful implementation outcomes.

- Most ideas are supply driven at the FBI research section.

- There is little to no incentive for academics to get products implemented into crime laboratories.

- Many government agencies (federal, state, and local) do not have a good surrogate for revenue to drive priority setting, and fiscal year money is often unknown from year to year. This makes long-term planning difficult.

Research is important: More efficient methods, more sensitive detection techniques and increased accuracy are all important in forensic science.

Key Points:

- Forensic laboratories have an obligation to explore and, where appropriate, implement new research if it results in testing that is more accurate or more sensitive.

- In some disciplines, cases are rarely challenged in court (e.g., DNA). This may be problematic as legal and judicial impacts of new techniques may not always be a priority.

- A mechanism is needed to inform researchers of current research needs and priorities. NIJ could fulfill this role since they are involved with funding both researchers and practitioners.

Partnerships and Research Collaborations are Critical: Research initiatives are more likely to be successful when there are forensic practitioners involved. For example, the best firearm research efforts typically have casework examiners on their teams.

Key Points:

- If practitioners are on NIJ research review panels, money will be going in the direction of purpose-related projects.

- Grants are more likely to get approved if practitioners are included as part of the research team.

- Consider including lawyers as part of a research team. 
- CSAFE researchers have to select a partner crime lab. Labs have said they don't want to participate. Reasons for this refusal should be investigated.

- Explore how researchers and bench analysts might be inclined to get together for training and collaboration.

- Working groups are beneficial.

Validation: Validation involves performing laboratory tests to verify that a particular instrument, software program, or measurement technique is working properly. Confidence in forensic results is obtained by conducting validation studies. Validation studies provide objective evidence that the method is robust, reliable, and reproducible.

Key Points:

- DNA has set the gold standard that a lab has to validate everything.

- The barriers to validation include:

$\circ$ Knowing the number of samples to test

- Lack of guidelines regarding specifics of validation

- All forensic disciplines have the same issues regarding validation

\section{National Forensic Laboratory/Institute:}

Key Points:

- The FBI has served as an informal National Forensic Lab. Is this a good idea or a conflict of interest because they are mostly the prosecution side? (Note: FBI is a component of DOJ)

- Could a National Forensic Laboratory/Institute serve as an external validation team doing validation? Could you use someone else's samples for your validation?

- What about sending people to other labs to train? This used to be available at the FBI and in FL but there are not that many opportunities today. Only webinars, etc., not a two-way exchange.

- This organization could be unbiased and translate recent research for forensic labs, etc., to bridge the gap from research to the labs.

- Validation services team as "Forensic Storm Troopers" who come in and perform validations for busy laboratories.

Papers and Publications: Peer-reviewed publications are an important method of communicating novel ideas to stakeholders. However, busy forensic scientists often do not have time to go through all of the journal articles.

Key Points:

- Approximately 5,000 articles are published in 250 journals every year.

- Because of the sheer volume of publications, having an organization organize and summarize the publications would be helpful to busy forensic practitioners.

- ASCLD inspectors visit forensic laboratories and could potentially be a good source for sharing forensic best practices with the forensic community.

- Research disappears in a sea of papers. Forensics professionals might not know about research in other fields that could help them. 
Proceedings of RI2I Symposium, NIST Gaithersburg, MD, June 19-20, NIST SP 2100-02

- The FBI produces 12 to 15 publications a year. They want to publish in high-impact journals. The impact of the journal where the papers are published is as significant as the research findings.

- Journal articles are too complicated for people not in that field of study. Information needs to be accessible to more general audiences.

- People get caught up in their own disciplines and don’t learn about other fields.

- Many government agencies have limited budgets and cannot invest in sending forensic practitioners to professional meetings.

- Research Gate is used to archive and find journal articles. Washington state also has a library service that collects journals and publications.

- Many young forensic professional employees are focused on impacting case work and advancing within their organizations. Committing the time and energy required for bringing new capabilities into their labs (e.g., reading peer-reviewed publications) may not be a priority.

\section{Quality Systems and Infrastructure:}

$\underline{\text { Key Points }}$

- NIST participants reported that quality control manuals can be a barrier if they are method based, not performance based.

- Data sharing between labs is difficult due to different SOPs, commercial kits, etc.

- NIST participants encouraged performance, as an alternative to methods.

- Quality systems can be a barrier because they are strict and are required for accreditation.

- Certification is a barrier because it takes up too much time, money, etc.

- If a new technology is introduced, it takes a while for new standards to be created and you cannot be accredited for it, so it is hard to get new technology done quickly.

- How many Daubert Hearings are needed to say enough is enough and for a new technology to be accepted in the courts.

At the end of the discussion, the group was asked to prioritize barriers to the implementation of new research in forensic laboratories. A majority of the respondents (90\%) said the largest barrier is in the translation of research into the crime laboratory. The remaining $10 \%$ said that the lack of a surrogate for revenue from the government was the largest barrier.

Potential Solutions: The overall outcome of the discussions highlighted the need for a centralized resource(s) that would offer implementation services to forensic laboratories:

- Creation of a centralized area or agency for protocol sharing

- Creation of a federally funded validation services team

- Creation of a forensic clearinghouse or analogous mechanism for sharing information from field practitioners. 
Proceedings of RI2I Symposium, NIST Gaithersburg, MD, June 19-20, NIST SP 2100-02

\subsection{Laboratory Management}

Implementation of new technology into a laboratory used to be easier than it is today. We have a lack of synergy among government agencies, private companies, and academia. Creating a strong rapport with private companies allows the two-way benefits: laboratories get extra support from the company, and the company gets feedback to improve its product. Both get to increase their exposure. Research is needed to address issues of accuracy, reliability, and validity in the forensic community. Validation has many definitions; one single definition needs to be identified that can be used across the field. Laboratories need to train, qualify, and proficiency test their analysts to maintain accreditations. The admissibility of scientific evidence in the courts should not be a reason to deny new technologies in the laboratory. Laboratories cannot risk falling behind in technology for fear that they will not be able to explain themselves in layman's terms on the stand. Information and training should be provided to investigators, attorneys, and courts to be aware of the advantages and limitations of new methods and technology. It is imperative that management is also aware of this information because if they are not on board with the new technology, it will be difficult to obtain.

\section{Group Discussion}

The discussion group consisted of 23 participants from many crime laboratory disciplines. The group included participants from international groups, federal, state, and local agencies, and accreditation bodies. The discussion began with answering the question, "What barriers do you encounter with implementation of new technology as it relates to laboratory management?" This led to a very productive discussion in which participants identified common themes that related to those barriers. The following barriers were identified:

Laboratory Needs: When new technology is created, it is often done without input from a lab. This leads researchers to create technology which is often too "fancy" for what the lab needs. All the extra "bells and whistles" drive the cost of the technology up and make it hard to justify for purchase. Additionally, with some disciplines, new technology is so abundant that it's unclear what might be good for any particular laboratory's needs. Laboratory managers don't have the time to research all the new technology to determine the best fit. When laboratories have interns come in and research the new technology, the laboratories end up with a plethora of data that managers don't have time to sift through.

Training and Education: With the adoption of new instrumentation, laboratory managers are concerned with the potential for steep learning curves with staff who have been using the same methods and instruments for years. Upper-level staff and lab management then become concerned with the stress and potential backlog that will fall on their staff. An additional concern was the lack of centralized extensive training for staff that used to take place. If this type of training could take place again, staff could slowly train on new instrumentation and methods to avoid case backlogs.

\section{Key Points:}


Proceedings of RI2I Symposium, NIST Gaithersburg, MD, June 19-20, NIST SP 2100-02

- Some of the smaller lab systems will suffer because they tend to have staff that have been in their positions for many years and probably haven't had to use or learn statistics since leaving school.

- There needs to be a central lab to standardize new technology and training, which then offers that training to keep everyone on the same page. Training can be given to one user in the laboratory who can then train additional users.

- Training needs to be in place so that users understand the limitations of the equipment.

- For some disciplines, such as impression forensics, there is going to be a steep learning curve with new technology because the current technology has been used for 15+ years.

- Once staff begin to see the results of a new implementation, the growing pains of becoming adjusted will lessen because they see for themselves how the new technology will help their laboratory.

Caseload: Adding new technology to a lab not only adds to caseload because of retraining staff but also because more tests might be requested simply because the technology is new. Additionally, there might be out-of-jurisdiction case requests because other labs don't have the new technology.

\section{Key Points:}

- With new technology such as touch DNA, the caseload increased exponentially - the availability of the technology created a demand for the testing.

- More funding through the state to support fee-for-service would lessen caseload backlogs and free up forensic scientists to implement new technology.

- Laboratory managers are concerned that if an analyst is taken off the bench part-time for 6 months to do training on new instruments and validations, backlogs will happen.

Procurement: One of the main issues in implementing new technology has a lot to do with the procurement processes and requirements that many laboratories have in place. One of the first and foremost issues with procurement is the cost of a new technology. There can be difficulty in justifying to upper management why new instrumentation is needed. Lab management has to identify the risks and opportunities and present why the purchase is a necessary investment.

Key Points:

- Restrictions - A laboratory is offered new technology to use free-of-charge for 6 months to contribute to research and revision of the product. They are unable to accept this offer because if they do the laboratory would be barred from purchasing from that company for a significant length of time.

- The sole-sourcing process can be very difficult even when only one vendor exists.

- Upper management often thinks additional staff will fill the needs of the laboratory, but it is equipment that is needed. 
Proceedings of RI2I Symposium, NIST Gaithersburg, MD, June 19-20, NIST SP 2100-02

- Information technology (IT) staff need to be involved in the procurement process early on, especially when new implementations are drastically changing the IT needs of the laboratory.

- If you had all the data you needed (cost, reliability, speed, etc.) it would be easier to justify the spending, but that information is not always readily available or easily calculated.

- Everyone wants to be cheap. A lab has all the expertise and the equipment; if you want them to help you, it costs.

- Can laboratories use existing backlog issues as a catalyst for getting new technology?

- DNA is in the forefront of the public eye and has advancements seemingly every year, but other disciplines, such as latent prints, can identify people more quickly and cheaply than DNA. If we can make an effort to substantially advance other disciplines, it can help alleviate many of the problems we see with backlogs and procurement.

- In DNA, the technology is always changing, which makes it difficult to justify spending money on a new technology when the same thing was just done a year ago.

Validation and Standardization: The biggest barrier discussed regarding implementation of new technology was validation and standardization. Often with new technology, the validation process can be very lengthy because each laboratory "recreates the wheel" when it validates: there are no standards or guidelines to follow for new technology. The amount of work that would be required to validate, implement, and create internal guidelines within a single laboratory often discourages the procurement of new technology.

\section{Key Points:}

- When the validation process takes too long, analysts get frustrated and end up just using processes from 30 years ago.

- Some labs still follow validation from years ago even though the technology has improved.

- People become comfortable in overworking validation or dismissing it because they didn't realize the shortfalls of the new technology.

- Validation being done in their own laboratory gives staff the comfort of knowing the validation was done where the casework is also being done, which helps when someone is needed to testify.

- The Scientific Working Group for Forensic Toxicology (SWGTOX) has developed validation guidelines, but these guidelines only apply to toxicology.

- Standardization even within a lab is difficult.

- In Australia, some national decisions are made regarding changes in technology and methodology, but some are optional. In general, it is ideal when all labs make changes at the same time. 
Proceedings of RI2I Symposium, NIST Gaithersburg, MD, June 19-20, NIST SP 2100-02

- Sometimes there are standards for the same instruments being used in non-forensic disciplines, but there is no incentive to use those standards.

Communication: A barrier exists that prevents communication between laboratories and researchers. For instance, researchers often don't understand the IT needs and limitations that exist in a laboratory and they create technology that cannot be implemented. Academics are unable to provide actual practice data for new instrumentation. There are also communication issues between the court system and laboratories: it's not always clear what information needs to be disseminated.

\section{Possible Solutions}

Resource Sharing: The group discussed the potential of a central organization which would identify trends and evaluate research, then disseminate this information to laboratories with recommendations for new technology. Additionally, this organization could help to create validation guidelines and standards for use that laboratories could follow. Another option discussed was to have laboratories coordinate regionally: each laboratory could buy one piece of equipment to share with the others. Regional co-ops might also lessen the time laboratories spend validating if one lab does the main validation on a new technology and then disseminates that information to other laboratories who can do site validations when they procure that new technology.

External Pressures: The group discussed the possibility of using external pressures from the media, prosecutors, and legislators to hasten procurement. Laboratories need to adhere to the Daubert standard or the Frye test, which may require the acquisition of a new technology so that the laboratory maintains the best technology.

\section{3. $\quad$ Business}

Eleven private businesses were represented by 17 participants, with backgrounds in equipment, consumables, and service laboratories. The Business break-out group discussed the barriers to implementation of innovation. While the topics spanned multiple areas, the group did agree that the barriers could be arranged in four groups: Risk, Trust, Budget, and Priorities. The four areas were ranked in order of overall impact.

Risk: From the group discussion, risk was identified as the greatest barrier to implementation. Laboratories and forensic analysts typically don't want new technology or methods that are not proven, which is referred to as "early-adopter aversion.” When technology and methods are already established there is the opportunity to learn from others' mistakes, presenting less risk. 
Proceedings of RI2I Symposium, NIST Gaithersburg, MD, June 19-20, NIST SP 2100-02

Key Points:

- Research and development are timely processes, so there is a risk that the new technology might be "old news" by the time implementation is complete.

○ How do we maintain competency while balancing casework?

- People are comfortable in their current processes and don't like change.

- There is risk involved in the process of gaining legal acceptance.

- There are no standards - how do we make sure it is being done "right"?

Trust: Often ideas don't manifest into the exact reality expected. There are real differences in research and production, especially when considering process flow, training, and testimony. Quite often, the advertised benefit(s) of the new technology does not transcribe into casework. Finally, the laboratories and the analysts must trust that new technology (and its implementation) is sound, reliable, and can be defended during testimony.

\section{Key Points:}

- Vendors should provide the customer with the sales and technical support required for new technology implementation.

- Better understanding of the life cycle of the new technology is crucial.

- How long will it be relevant?

- Laboratories need to trust that the proposed and advertised capabilities of the new technology will be realized within their current operations.

- There has to be trust that the laboratory has the capability to successfully implement all aspects, such as IT infrastructure, human resources, and training.

Budget: Another barrier to implementation is budget. Laboratories have to consider their return on investment, including upfront and long-term costs, time considerations, IT impact, quality system changes, and training.

Key Points:

- While often preferable, especially with changing technologies, lease or financing options are often not permissible for public laboratories.

- When permissible, borrow or lease programs are beneficial as they allow laboratories the opportunity to more appropriately measure the impact to budget.

- Budget considerations are not simply financial. They also include: proficiency testing, training requirements, impact to the quality assurance/quality control (QA/QC) system, LIMS and IT systems, consumable changes, and impact to "approved vendor” lists.

Priorities: The group discussed that management and laboratory priorities are often not aligned. For example, laboratory managers may be focused on cost or throughput while the 
Proceedings of RI2I Symposium, NIST Gaithersburg, MD, June 19-20, NIST SP 2100-02

analysts and QA/QC managers may be interested in failure rates or limits of detection. Oftentimes, these differences in priorities may not be clearly established and understood. Finally, it is not uncommon to find situations where the legal jurisdiction/community may have different priorities than the laboratory.

- Market Demand: The term "market demand” is used to describe the overall expectations of the service base/area, including legal/court environment(s), citizens of the service area, law enforcement agencies served, and regulatory stakeholders.

Key Points:

- Market demand is strictly a financial measurement for for-profit entities, but not necessarily for a publicly funded labs.

- Market demand is dependent on the perspective of an agency or person.

- It is very difficult to properly measure risk or adequately budget for it without understanding and measuring market demand.

- Forensics is a small market: many products have been developed for other industries and then re-marketed to forensic science, which can limit innovation.

- Businesses are limited as a small market, but people also have a desire for new products (it is a two-way street).

$\circ$ Measure market demand with community engagement and focus groups for clients.

○ Vendors can (and should) work with forensic laboratories.

Other barriers discussed: Other topics of discussion included evaluating and mitigating privacy risks generated from new technology as well as scientific value, politics, and caseload capacity. Forensic science is more reactionary than proactive. Forensic science follows the market rather than driving it.

\section{Possible solutions}

Life Cycle: Vendors can provide more insight into expected life cycle times or help create backwards compatibility with new innovations.

Acceptability: The availability of independent, third-party validation, especially from a clear authoritative source, can help laboratories lower the perception of risk and court acceptance.

Subject Matter Expert/Decision Influencer: Laboratories could use a subject matter expert (SME) or a decision influencer to inform and influence solutions for the laboratory based on periodic reviews of the laboratory's needs. This would allow laboratories to have an outside, unbiased perspective on what new technology might be beneficial to operations. 
Proceedings of RI2I Symposium, NIST Gaithersburg, MD, June 19-20, NIST SP 2100-02

Training: Having vendors provide training and/or proficiency testing would take a large burden off of the laboratories and would help them be more confident that their training is correct.

Measuring Market Demand: Developing better tools and systems for publicly funded entities to regularly measure the market demand of its service area.

\subsection{Legal}

The majority (>95\%) of civil and criminal cases in the United States (and likely in most countries) are resolved without the case proceeding to trial ${ }^{3}$ and, thus, proceed without the need for expert testimony and a trier-of-fact (generally a judge or jury) to decide a verdict in the case. New forensic science techniques and results provided by oral communications or via reports may not be very relevant or important contributing factors to many of these resolved cases. Or, if relevant to the case, the decision to resolve the case prior to trial testimony occurs without a concern for the admissibility of the new innovation and the testing is simply accepted as part of the adjudication process.

When the reliability of new scientific processes or data in general, and/or as it applies to a particular case, becomes an issue for the court, then US Supreme Court cases (e.g., Daubert and Frye), regional cases, and state statutes control the legal requirements for the admissibility of scientific evidence. It becomes imperative for the attorney who is the proponent of the evidence seeking its admissibility to work closely with and have effective communications with the forensic (and possibly research) scientists to lay the appropriate scientific groundwork for each of the legal requirements so that the judge will decide to admit the evidence. Similarly, forensic scientists and researchers may work with opposing counsel to raise challenges to the scientific and legal aspects of the technology or test procedures.

Admissibility hearings can be quite costly to the system to have the hearing, retain experts, and provide discovery. Additionally, forensic scientists spend time both in and out of the laboratory and working with courts to get appropriate training and become familiar with the scientific and legal requirements, write reports, and/or file relevant briefs. After a hearing there are also likely to be additional time commitments during the subsequent appeals process. Because of the costs, admissibility hearings may be primarily reserved for more high-profile or serious cases. The novelty of the technology and its differences/similarities to existing technologies will influence the need for an admissibility hearing; thus, slight modifications to existing technologies may not be viewed as innovations requiring an admissibility hearing, whereas the introduction of more novel technologies with significant scientific and/or evidentiary impact increases the likelihood of having admissibility hearings.

3 Generally, either by the charges being dropped or the case being resolved through a settlement or plea agreement. 
Proceedings of RI2I Symposium, NIST Gaithersburg, MD, June 19-20, NIST SP 2100-02

Experts in certain forensic disciplines (e.g., blood alcohol, drugs, toxicology) are much more likely to be required to testify during trials whereas forensic scientists in other disciplines (e.g., DNA testing) are not called to court nearly as often. Due to the accusatorial system of the courts, the exposure of the experts in trials and admissibility hearings may create an adversarial culture that increases the risk of exposing the laboratories and the individual scientists to criticism and uncomfortable situations. This adversarial culture and the constraints of the testimony process may have an impact on the appearance of neutrality of the scientist both in and out of the courtroom.

The juncture of science and the law is most acute during admissibility hearings and trials involving forensic science evidence. Mutual understanding of the requirements and responsibilities of both the scientific and legal entities for effective communication is critical to the success of the criminal justice system.

\section{Group Discussion}

This was a small discussion group with eight participants:

- Several lawyers

- A judge

- The UK Regulator

- A practitioner

- Several individuals from NIST’s Special Programs Office

- The international perspective from the UK and Australia.

The group discussed and prioritized the top barriers and factors impacting the introduction of new innovations into the courts. A common theme was that these barriers cannot be considered separately as they are interconnected (see Figure 1). 


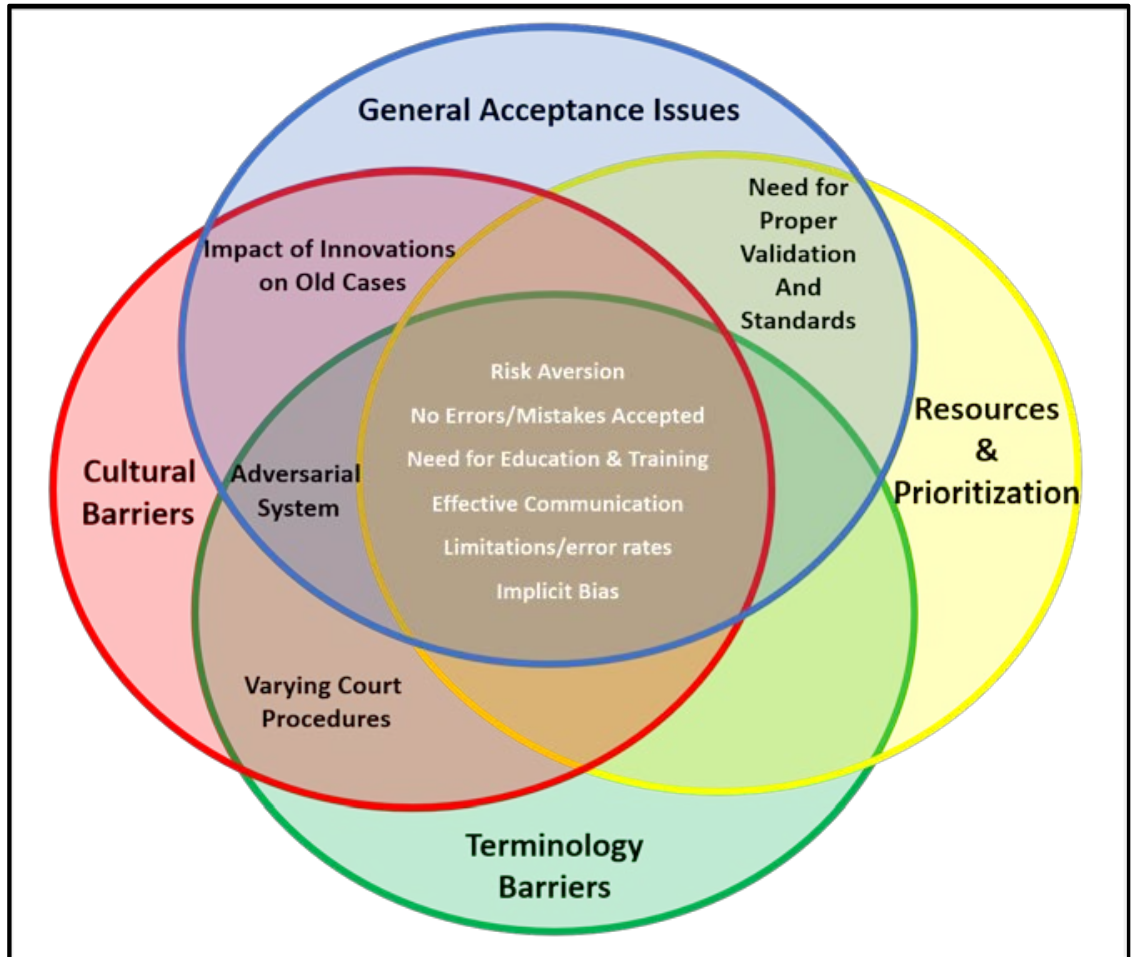

Figure 1. Court Perspective on Barriers in Implementing New Technology

The highest priority barriers identified include the following:

Culture and Education: The accusatorial nature of the court engenders an adversarial culture between opposing counsel that often directly impacts forensic scientists. This adversarial process affects the perceived risks to the laboratories and the individual forensic scientists, often impacting the introduction of new technologies into the laboratory and the courts as well as testimony during trials. Education and training are critical elements for the admissibility of innovations into the court. The scientists, the attorneys, and the judge involved need additional education and training in the scientific method, terminology, and procedures used as well as in the legal requirements for admissibility and for presentation to the trier-of-fact. A key component of education and training is understanding the scientific and legal terminology and having effective communication among the triad of the scientists, the attorneys, and the judge.

\section{Key Points:}

- Scientists need to be knowledgeable about the legal requirements for court admissibility.

- Attorneys need to be knowledgeable about the scientific limitations of a test system and recognize that ALL processes have inherent limitations and strengths that must be effectively communicated.

- Scientists must look for and define the limitations of the test system, design their procedures and SOPs appropriately, and communicate effectively.

- All parties of the criminal justice system must recognize that errors and mistakes are going to happen and acknowledge the strengths vs. limitations of the test system. 
Proceedings of RI2I Symposium, NIST Gaithersburg, MD, June 19-20, NIST SP 2100-02

- The limitations associated with errors and mistakes may have no or minimal/irrelevant impact on a particular test.

- Change in culture that embraces the limitations of the science and its technologies and acknowledges the inherent measurement errors and limitations is needed.

- Better communication, education, and acceptance of the limitations of the science as part of the process are critical components.

- The potential impact on the laboratory and/or an individual's reputation and career for censuring when inherent/expected issues occur needs to be recognized.

- Scientists should not be "weaponized" if they make mistakes.

- The pitting of scientific experts against one another should not result from the adversarial nature of the legal system.

- Recognition that there is inherent/implicit bias of each person in the criminal justice system based on background and education.

- Judges may appoint experts for the court to assist in understanding forensic science issues.

- Experts can be asked by the judge to state what they agree on and where their opinions differ, similar to what is done in other countries.

Proper Validation: The group recognized the critical need for having well-conceived and robust validation studies, both during development of the innovation and prior to implementation in the laboratory. The studies should be as strong and as thorough as possible and include multi-laboratory participation, including international laboratories.

Key Points:

- Validations need to have "bullet proof" and published research done initially.

- Laboratories have to clearly define the strengths and limitations inherent to the process of validation.

- Acceptable error rates need to be defined.

- Evidence worthy of testing (e.g., fresh vs. old; effects of storage) needs to be clearly defined.

- There needs to be an established set of standards for validation.

- Development of appropriate standard protocols is needed.

- The results of validation studies, including the strengths and limitations, should be communicated/disseminated.

- Validation studies need to be critically peer reviewed.

- These objects should be fairly easy to achieve if appropriate resources are available.

Resources and Prioritization of Resources: The availability of appropriate resources is critical for the proper implementation of new technologies in a laboratory and subsequent admissibility into the court. The limitation of resources may require prioritization of the needs of the laboratory and the court, and may impact decisions regarding implementation of new or modified technologies into a laboratory, and its subsequent admissibility into the courts. 
Proceedings of RI2I Symposium, NIST Gaithersburg, MD, June 19-20, NIST SP 2100-02

\section{Key Points:}

- Sufficient resources are needed to address the scientific and legal requirements for admissibility

- Areas where critical resources are needed include:

$\circ \quad$ Funding to meet the needs of the laboratory implementation (e.g., doing proper validation studies, developing standard protocols, purchasing instrumentation and materials, IT and facility requirements, having appropriate samples to test).

○ Funding to have an admissibility hearing (e.g., retaining experts to consult and testify; providing discovery).

- Notice of emergent use of new technology is needed to retain experts, provide discovery, facilitate review and have admissibility hearings (Note: This may create logistics issues).

○ Funding and time for education and training of laboratory scientists, attorneys and judges is essential.

- Availability and time for appropriate personnel in the laboratory to implement the innovative technology and for the attorneys and scientists to prepare for and appear in an admissibility hearing and trial.

- Recognition of case management issues and acceptance that other cases may not be processed by the laboratory and/or the courts during this time (i.e., backlogs may occur during the introduction of innovative technologies.

- Cost-benefit analyses may need to be performed.

- Prioritization of resources to meet relevant needs may be necessary.

Risk Aversion: The legal system in general is risk averse. Acknowledgement of test limitations, errors and mistakes, the recognition that there are inherent error rates in tests, and the concern over an injustice in the courts all create angst for the scientists, attorneys, and judges involved in the criminal justice system. The need for finality in the courts and the issues associated with the introduction of new technologies or recognition of errors that may impact resolved cases are significant concerns.

\section{Key Points:}

- Laboratories and the courts must accept that:

$\circ$ There are inherent risks in tests and that no test is perfect.

○ There are limitations to all tests and those limitations should be well-defined.

- There is an inherent error of measurement and error rate for any technology/test/assay, and these measurement errors do not constitute mistakes.

- Laboratories must be open to admitting that mistakes/errors can happen both in the laboratory and in the courts (e.g., contamination, human error).

- There needs to be a very low, but acceptable rate of error.

- Research and validation studies should address the mitigation of errors during testing. 
Proceedings of RI2I Symposium, NIST Gaithersburg, MD, June 19-20, NIST SP 2100-02

- Proper procedures, with appropriate controls and precautions, should be used to detect and limit errors.

- ISO 17025 has a risk assessment component that laboratories must address.

- Education and open communication are key components to managing risk.

- The context of the limitations, measurement errors, risks, and errors/mistakes is critical to understanding their meaning and potential impact.

- Clear testimony regarding the limitations, measurement errors, errors/mistakes, and precautions taken to mitigate issues is key.

- Scientific witnesses should not be weaponized because of limitations of the test and/or errors associated with the test.

- There is a need to find a balance between the use of acceptable new technologies that aid investigations and assist the trier-of-fact, with the risks associated with potential unintended consequences of the new technologies.

- Retrospective evaluation of resolved cases may be necessary when new or improved technologies are available to the criminal justice system.

Effective Communication: It is well known that scientists and lawyers tend to speak "different" languages, which is complicated by the fact that the same term may have different meanings for the two sets of professionals. Successful admissibility of innovations into the court necessitates effective communication with a clear understanding of the terms used by all parties. Once the evidence evaluated using the new technology is admitted into the court, clear presentation of the scientific evidence to the trier-of-fact is then critical for the adjudication of the case.

Key Points:

- Recognition of disparities in the use of terms/terminology for scientists and lawyers is important; the same words have different meanings, resulting in scientists and lawyers often talking at cross purposes.

- Lawyers generally do not have the time and background to learn science and math quickly.

- Generally, scientists do not have the time and background to learn about the law quickly.

- All parties need additional education and training in both the scientific and legal issues associated with having an admissibility hearing and the subsequent presentation at trial to the trier-of-fact. Adequate funding for relevant training and time for the training and court preparation are essential for the criminal justice system to function effectively and appropriately (see Resource issues above).

- It is beneficial for scientists and attorneys to meet in person and openly discuss scientific evidence.

- Evidence that may be probative from the attorney's perspective may not be suitable for testing or provide meaningful results.

- Scientists must be honest and objective about the strengths and limitations of the science and technology in general, and specifically for any associated with a particular case, and communicate effectively to the attorneys, judge and jury. 
- Scientists should only be advocates for the science and the accurate presentation of the science in court and not be proponents in the case.

- Highly trained, competent scientists are essential when presenting the trier of fact with accurate scientific evidence within the proper context.

- Ethical dilemmas may result when scientists are unable to adequately answer questions or provide relevant information during testimony due to the questionanswer format of testimony.

“General Acceptance” and Varying Procedures for Courts: There is no agreed upon definition of "general acceptance" in either the scientific or legal communities, yet it is one of the common criteria for the admissibility of new and novel technologies in court. Courts in different jurisdictions have different legal requirements for admissibility based on the controlling US Supreme Court or state case rulings and/or based on state statutes.

Key Points:

- It was noted that inconsistencies in scientific and legal requirements for admissibility are likely to exist in different jurisdictions, and even by different judges in the same jurisdiction.

- The variation in admissibility may lead to inconsistencies in the resulting rulings by judges, even in the same jurisdiction, due to differences in interpretation of law.

- The group acknowledged that technologies established in other scientific communities prior to adoption in crime laboratories (e.g., DNA testing with wellestablished medical applications) may be more easily admitted into court due to the precedents established outside of the forensic community. The admissibility of technologies primarily having forensic applications may proceed in a different manner.

- While having an accepted definition of "general acceptance” would be helpful, the group recognized that this is a difficult proposition with limited ability to resolve.

Testing/Retesting of Old Cases: This was recognized as a high-priority issue to consider during and after the implementation of new technology into the laboratory and acceptance into the courts, however, it was generally felt that this factor would have minimal impact on the initial decision to implement or admit the new technology.

Key Points:

- If the new technology functions appropriately with older evidence, various parties of the criminal justice system may need to consider:

o Re-opening unsolved cold cases for testing if evidence is available that may assist with solving the case.

o The possibility that previously untested evidence in post-conviction cases may now be suitable for testing and/or the re-testing of evidence in postconviction cases if the new technology offers improvements (e.g., increased sensitivity, detection of polymerase chain reaction (PCR inhibitors) or suggests that the previous testing may be flawed in some way. 
Proceedings of RI2I Symposium, NIST Gaithersburg, MD, June 19-20, NIST SP 2100-02

o The decision to do re-testing should be made by law enforcement and/or attorneys in consultation with the laboratory.

o A plan to prioritize testing or increase resources to avoid backlogs if retesting of older cases is likely.

While the ability to do testing in old cases may raise the concerns of "opening the floodgates" for additional testing, the group agreed that taking a retrospective look at older cases needed to proceed and that any resulting issues would need to be dealt with in an appropriate manner. Not doing the retrospective testing was viewed as an unacceptable decision.

\section{Breakout Session B}

Participants were given readahead material (Attachment E) on the use of the liquid chromatography quadrupole time-of-flight mass spectrometry (LC-QTOF-MS, QTOF for short) in toxicology laboratories to identify fentanyl isomers using nontargeted analysis. Participants were asked to use their real-

QTOF vs. Immunoassay

- Although QTOF can provide a singular comprehensive method to detect the presence of hundreds of analytes in any bodily fluid, the importance of quantitation cannot be understated. The mere presence of an analyte may or may not be probative without knowing the concentration.

- If the laboratory is using QTOF for screening, it can limit the validation to only type I and type II errors (false positives and negatives). This is much simpler than validations for quantifications.

- $\quad$ Labs have to decide which methods to validate based on need. world experiences to go through the process of implementing the QTOF in a laboratory, discuss the barriers to implementation, and to think about what solutions would solve those barriers.

\subsection{Group 1: Charla Marshall Facilitator}

For this breakout session, we had 18 participants comprised of latent print examiners, chemists, court personnel (judge and prosecutor), private companies, accreditation group, and government agencies (FBI, Secret Service, NIST). The group began with a discussion of the LC-QTOF-MS and asked experts to explain the technology to the group. Several scientists did, stating that it offers a resolution of fentanyl and other isomers through enhanced detection capabilities. The scientists explained that they would use the technology in a research laboratory, perhaps to understand chemical structure or develop standards that could be used in the broader community. However, they did not indicate that the QTOF was a vast improvement over the triple-quad technology that is now in broad use throughout the forensic toxicology field.

The group then moved to several discussion points regarding whether or not to implement a technology such as QTOF in a practicing laboratory. 
How much of an improvement is this technology? It is good for drug screening but limited in quantitation. You can screen for many drugs today, as laboratories are already using triple quads, which has the same functions as the QTOF, so it is undetermined how much of an improvement this technology brings.

Is it better for isomer detection? Yes, but it may be useful as a supplemental test instead of a primary one. The NIST Mass Spectral Library is based on single quad. The QTOF is a triple quad, so that might be a barrier to making comparisons.

Does it give the scientist higher confidence in their results? It helps with fentanyl analogs. Analogs change often in drugs on the street. Analog identification affects the criminal charge. It is necessary to identify the analog to identify the extent of the market. Therefore, analog identity has a public safety effect.

Additional points regarding whether or not to implement a technology such as QTOF in a practicing laboratory included:

- Do the manufacturers have their own library for standards and comparisons?

- More research labs are using triple quads instead of QTOF.

- NIST does studies on LC-MS technology, but can they recommend a specific instrument?

- Is there an NIJ requirement to share data produced from grant work?

- There was a lawyer's example of too many choices and different ways the process is being done, which makes trials confusing. Can we streamline this better?

Following QTOF-specific questions, the group began to identify barriers experienced in QTOF implementation:

Justification and Costs: Is the implementation worth the time and money? To determine whether to spend the money, laboratories need to run a cost-analysis to justify procuring a new technology. They need to incorporate return on investment (ROI), installation time requirements, training requirements, validation processes, peer review, funding sources, collaborations/memoranda of understanding (MOUs), casework impact, vendor options, as well as others. Performing a literature review might be a helpful tool in justifying new technology. At times, laboratories have to keep in mind that value is not always monetary. For example, with the Combined DNA Index System (CODIS), the value is in public safety.

Communication: There is a need for collaboration between vendors and labs, which would allow true crime laboratory samples to be used during research to ensure the new technology can function properly on real-world samples. Often times, these samples are difficult to obtain. Researchers are not always at liberty to discuss everything about a technology due to restrictions set by the funding source. This can make it difficult to trust in the technology - is 
Proceedings of RI2I Symposium, NIST Gaithersburg, MD, June 19-20, NIST SP 2100-02

it being done right or to make money? The public safety impact of new technology is important and must be effectively communicated. This encompasses explaining to the courts what the technology is capable of and what can be tested. Between laboratories, data sharing needs to be easier and more widespread.

Additional topics of discussion regarding barriers:

- Do labs have the moral obligation of validating and implementing a new technique if it is more sensitive or would result in increased matches and/or criminal outcomes?

- Issues associated with running a side-by-side pilot study to see how useful the new technology is and how different it is from what is currently in use

- Is there an obligation to sell a product after so much R\&D money was spent on it?

- Under what conditions can the general acceptability of a technology come into question. If just a minor change is made to the technology, does its acceptance need to be re-established?

- Libraries and standards may be the intellectual property (IP) of the vendor.

- Setting up MOUs, Materials Transfer Agreements (MTAs) and Data Transfer Agreement (DTAs) can be difficult.

- Small forensic market, so not much competition overall.

- The forensic market is often a side market of larger companies.

After speaking about the barriers to implementation with the QTOF, the group then discussed another example of a new technology to compare and contrast the barriers and challenges of implementation. Probabilistic genotyping was discussed in relation to research to innovation challenges and the following points of discussion were brought up:

- Would validation be completed more quickly if it wasn’t a novel technology but just a change in methodology?

- Education is important overall, and lab experience during graduate school should utilize the most relevant technologies.

- Overhaul technology (e.g., probabilistic genotyping, next generation sequencing (NGS)) may differ from technology that offers a small improvement. The urgency to implement an overhaul technology can be different and the results need to be obtained more quickly.

- Are you going to use the new technology on all samples at your lab or just some of them?

Overall, the group agreed most new technologies share the same challenges and barriers to implementation. Collaboration, government support, and communication would help facilitate a more streamlined approach to innovation and successful implementation. The following key points were identified regarding implementation of new technology: 
Proceedings of RI2I Symposium, NIST Gaithersburg, MD, June 19-20, NIST SP 2100-02

- The benefits and limitations of new technology need to be transparent and understood by all parties.

- The audience should include forensic science practitioners, the public (in terms of public safety), the courts and legal side, administrators, grantors, and other scientists.

- Pilot studies are important as a first step.

- Test the new technology with actual samples before implementing it.

- Perform a cost-benefit analysis.

- Determine the value of implementation.

- Collaboration of vendors, labs, and NIST is important for success.

\subsection{Group 2: Lawrance Mullen Facilitator}

For this breakout, we had 14 participants from laboratory personnel, federal organizations, lawyers, and an international perspective represented by Australia. Discussion began with asking which participants, besides reading the material provided, were familiar with the QTOF instrument. One participant was familiar with the instrument and another was in the process of having one installed in their laboratory at the time of the meeting. Participants were then asked to discuss the barriers to implement the QTOF in the real world. The most prominent barriers, which are very closely related to the topics discussed in Breakout Session A, are listed below.

Cost-Benefit: It is important to be able to show how the QTOF can save the laboratory money and in what time frame. In one laboratory, it has been possible to combine the jobs of two separate instruments into one. Manufacturers can provide address performance specifications that should result in anticipated cost savings. Real-world data on cost savings might be available from prior adopters. There should also be a holistic cost-benefit analysis that is carried all the way through the court and appeals system. Will the use of this new instrument lessen the time spent in court or the number of appeals that take place? A few participants agreed that many laboratories will not upgrade until the cost to implement the new technology costs less than the costs that would be incurred if they did not implement. A template or framework needs to be created so that laboratories can easily create these holistic cost-benefit analyses.

Key Points:

- Hoping that the QTOF can show what is missing with the current instrumentation in place.

- Hopefully, once purchased, the QTOF technology will last for many years

- Cost-benefit expands to courts and appeals, etc.; we need that holistic approach

- Is there a system-wide basis for this holistic cost-benefit approach?

- How can we make this happen in the forensic community?

- If you can do the job with what you currently have, why do you need the new technology?

- Where are the savings? How do you convince higher-ups that you need this technology? 
Proceedings of RI2I Symposium, NIST Gaithersburg, MD, June 19-20, NIST SP 2100-02

- As the technology is implemented more, it gets less and less expensive.

- What is the level of confidence needed to accept a new technology?

○ How do we measure this?

- Framework/template of a document to explain all those aspects (lab, business, legal).

- The report the researcher gives on the new technology is not what you use to justify to upper management the need for the technology

- When making cost-benefit analysis, keep in mind what do you need to do vs. what do you want to do.

- When obtaining a quote for new equipment, ask the seller about costs, past performance, etc.

- Keep service contracts in mind. If a laboratory has just one instrument, it might not have a service contract, which is usually $10 \%$ of the instrument cost.

Training: How do we ensure students are best prepared for working in a laboratory? There is often a disconnect between what is taught in master's level courses and what is being used by laboratories. If a university can't acquire a piece of technology, like the QTOF, that will likely be used in the laboratory, programs need to focus on at least teaching about it so that students are not unprepared upon graduation. Conversely, laboratories need to keep up with new technology because it could be all students are learning, then once they are hired these young staff haven't had training on the older instrumentation. This can also be frustrating to newly graduated employees because they may understand better than older staff how the new technology would benefit the laboratories, but they are unable to use it. This calls for a culture change. In the laboratory, it might be detrimental to train the entire staff on new instrumentation simultaneously. If manufacturers were able to train a technical lead and supervisor first, they could take the training back and slowly train the end users to lessen the burden.

Validation: Often laboratories are starting from scratch, though they are sometimes able to reach out to colleagues in other laboratories who have the same instrument for guidance. SWG-TOX has validation guidelines, but they don't explain how to design the validation tests, only what needs to be tested. This leads to laboratories interpreting in different ways, leading to very different validation techniques. It is not only hard to standardize validation across different jurisdictions, but also within the same parent agency, and even within one laboratory.

Communication: Quite a few participants mentioned that they had personal instances of investigators, lawyers, or court personnel asking for something to be done, based on what they saw on TV. Laboratories need a way to teach what is actually possible based on the technology they currently have. Sometimes there is no easy way to explain why a laboratory doesn't have the newest technology. It can also be difficult to explain to the court what tests are being done, especially on new instruments like the QTOF, and why it changed from a previous method. The information and explanations manufacturers give is directed at laboratory personnel, not non-scientific persons. We often need less-specific explanations for the court, which was easier 20+ years ago when the science was less complex. After identifying the barriers to implementing the QTOF, participants were asked about how the QTOF would affect their specific laboratories. 
Proceedings of RI2I Symposium, NIST Gaithersburg, MD, June 19-20, NIST SP 2100-02

Would the implementation of the QTOF instrument improve quality in your laboratory?

The resounding response is that yes, it would, as many of the laboratories have instrumentation that is much older.

Would the QTOF help your laboratory decrease processing time by 30 minutes?

For one laboratory, the QTOF will be replacing two separate instrument functions, so it should drastically reduce time. Other laboratories haven't yet tried to obtain the instrument, but think that after the transition period has passed, the use of the instrument will at least decrease processing time somewhat. It would be impossible to tell the exact length of time until the instrument was installed. If the QTOF can be used for other testing besides opiates, it may continue to reduce processing time.

When do you change your Standard Operating Procedures (SOPs)? Do system updates require updates to SOPs?

For most laboratories, updating SOPs is a quick process. Writing and updating SOPs is the last step of implementation, as it is done after validation is complete. It is impossible to know what the SOPs will be until the instrument can be used.

\section{Potential Solutions:}

When there are laboratories using the equipment, their proof of it working and savings should be used as justification for other laboratories to obtain the equipment. If laboratories with existing implementations could publish their results on the time- and cost-savings the instrument has provided them, it would help other laboratories.

A full life-cycle cost analysis is needed to address questions such as: what will it do in your laboratory, what are the true costs, where are the savings, are you going to get the results you need, what is the return on investment (ROI)?

Finally, there is a need for educating the courts and the public so that they are more aware of what technology is available and what exactly can be done with those instruments.

\subsection{Group 3: Ron Fazio Facilitator}

During Breakout Session B we had 17 attendees who were NIST chemists, vendors, and laboratory personnel, including representation from Australia-New Zealand. In discussion, we focused on the use of the QTOF instrument. In our group, one laboratory has the QTOF and is in the process of transitioning from immunoassay. The laboratory has a grant to look at different extraction techniques and needs to consider what drugs they are going to focus on, as well as considering limits of detection and false positives and negatives. After nearly one 
Proceedings of RI2I Symposium, NIST Gaithersburg, MD, June 19-20, NIST SP 2100-02

year into validation, they are considering how to process the data and how to make it easier for the end user to use.

Many of the participants said they would like to see more automation implemented into the laboratories. Discussion then moved forward to the implementation of the QTOF and the associated barriers.

Accreditation: There was considerable discussion of the need for new accreditation when adopting new technologies. It was generally agreed that re-accreditation wasn't typically necessary if the base technology or application to casework was not altered. However, when truly new technologies were used, or if used for new applications (i.e., QTOF used for nontargeted screening), re-accreditation was likely required. For this reason, changes in known technologies are relatively smooth but can be complicated with larger technological "jumps." If the technology changes, accreditation has to be re-established. This adds another step, which upper management or laboratories in general might shy away from, if what they are currently doing works. Not all labs are accredited, but accreditation should be the goal. Finally, there is not always an established standard for validation; having such would dramatically decrease uncertainty, especially in an accredited environment.

Vendor differences: Each vendor has its own data system. While most commercially available laboratory information management systems (LIMS) can accept data from a large variety of instrument vendors, there is not a wide variety of software that can organize and present the prodigious quantities of data generated from validation studies. The lack of such makes reviewing and validating new technology all the more difficult, even more so when using a new instrument vendor. Many laboratory personnel are comfortable using the data systems they already have in place, and they need to be properly trained so they are confident in their ability to use the instrument.

Risk: Laboratories have to understand whether an innovation is simply an incremental change or a true technological change. Incremental change, such as a new capillary column or new type of mass spectral detector, impart less risk, primarily because the base science has not changed. True technological changes involve new science or using an existing science in a new way. Additionally, technologies that produce objective results, such as a spectrum or concentration, are considered less risky because the results can be independently verified. Technologies that produce subjective results, such as pattern matching or color changes, are often more difficult, if not impossible, to independently verify. Participants disagreed on whether the QTOF is an incremental change or not; their existing laboratory processes influenced their opinions. Finally, higher specificity levels of a technology can also lower risk, in comparison to technologies with lower specificity. While the QTOF was not considered an incremental change, most participants felt this opinion was tempered by the 
objective nature and increased specificity of the data, especially when compared to immunoassay technology.

An interesting topic was "fitness for purpose." While this term was difficult to define, the group generally agreed that it meant whether or not the innovation was appropriate for the goals of the organization. For example, if the goal of the organization was to streamline process and reduce turn-around time, the implementation of a QTOF would have demonstrable value and therefore have less risk. If, however, the goal of the organization was to keep costs at a minimum or to minimize training needs, the implementation of a QTOF would have more risk.

Of course, risk is further compounded by other internal factors, including the number of qualified analysts, training levels of current analysts, future staffing changes, and other concurrent implementation efforts. Externally, it was agreed that risk is compounded by the local court environment and availability of casework that can be processed on the new technology.

Trust: Trust has to be a two-way street among all stakeholders involved (researcher, manufacturer, laboratory personnel, and management). Often, the drivers of trust vary from stakeholder to stakeholder, which can cause communication gaps. One stakeholder may place more trust in the ability of the vendor to provide timely service and repair, while another may place more trust in the ability of the vendor to accurately forecast consumable costs.

In general, drivers in trust include:

- The manufacturer's ability and enthusiasm in training analysts

- The manufacturer's previous success or failure with innovation

- The opinion of other laboratories with the same technology and testing scope

- Advertised capabilities of the technology

- Previous business with the manufacturer

- The manufacturer's post-sales support and technical support.

- The organization's own Purchasing Department's ability to source the correct technology and consumables necessary to properly implement.

Cost: Laboratories have to weigh the costs associated with instrumentation (instrument costs, consumables, validation, time considerations, etc.). However, the term "costs" is only relevant if considering the Return on Investment (ROI).

During discussion, it was noted that immunoassays are “cheaper” than the QTOF. When qualified, “cheaper” could mean capital (upfront) costs or operational (ongoing) costs. There were many who agreed that while a QTOF has a much higher capital cost, it was generally 
lower in operational costs. Interestingly, the group could not come to a consensus as to what was more important, capital or operational costs. The group did agree that, in general, private laboratories tend to prefer lower capital costs versus operational costs, while public laboratories were opposite.

Leasing equipment, while agreed upon as a favorable option, has generally only been available to private laboratories; public laboratories have rules that restrict leasing equipment. Participants agreed that adopting new technology would be easier with leasing. A few of the advantages identified included the ability to abandon failed initiatives sooner and upgrading technology faster.

The group discussed that there were often additional costs not initially identified, including;

- Data storage - Will the new technology require an increase in storage capacity or a new type of data storage?

- Security - If the technology produces significant new data, will there be confidentially issues that require additional security?

- Service costs - Some laboratories are unable to purchase service contracts. How will this new technology be maintained, especially if it is new or technologically complex?

- Personnel - Will the laboratory need to bring on new people? How long will it take or cost to find properly qualified personnel?

- Training - How long will the training take and what will it cost? Many laboratories lack a training budget (if grant-funded). What are the costs and backlogs caused by the need for increased training?

In general, while all agreed that formulating budgets and managing costs was not an undue effort, they needed better ways to identify and use ROI to accurately assess the benefit of an innovation. As discussed earlier, the real "cost” to an organization can only be truly assessed when that organization has defined goals. A technology that dramatically decreases turnaround time may not be cost-effective for a laboratory that is attempting to reduce error rates. A technology that has lower operational costs may not be cost-effective for a laboratory that is in start-up mode. For these reasons, most agreed that a laboratory should have clear expectations on the return, if not in financial terms, then in value.bbb

Policy and Competition: Often, laboratories have multiple initiatives in play. Resources are finite. What innovations will be supported?

Every laboratory has scarcity and limited amounts of a resource such as time, money, or even bench space. In addition, it is not uncommon for a laboratory to have multiple initiatives to 
Proceedings of RI2I Symposium, NIST Gaithersburg, MD, June 19-20, NIST SP 2100-02

consider at the same time. While these initiatives are often technology-related, they can also be expansions/relocations, personnel, or others.

The participants discussed the difficulty in executing innovation initiatives in competition with other initiatives. In general, all agreed that it is difficult to understand and quantify the evaluation mechanisms used by decision makers responsible for selecting initiatives. However, it was possible for most to identify factors used in consideration:

- Many managers tend to select initiatives that are easier for them to understand, such as those in disciplines they have direct experience in.

- Often the disciplines/lab sections don’t know the organizational goals.

- Laboratories are required to follow the specific jurisdictional oversight that is applicable in their community, which means that those factors must be articulated as goals are set.

- Laboratories come in all shapes and sizes; each has a different hierarchy and each level of the organization has specific (and sometimes differing) goals.

Finally, most participants agreed that their organization did not have a R\&D governance program. It was a general agreement that a separate, independent R\&D governance program could help prioritize competing initiatives.

\subsection{Group 4: Charlotte Word Facilitator}

Approximately 20 individuals participated in this break out session.

- The vast majority had research or business backgrounds

- There were few practitioners [CJW1];

- There were no participants from the legal community

- There were many individuals from NIST.

After discussions regarding the perspectives on the barriers for technology implementation into crime laboratories, several main overlapping and interrelated areas/objectives for overcoming those barriers to innovation implementation were identified. These include:

Demonstration of Needs and Risks: The group recognized the necessity of defining the specific needs and associated risks at each level to include:

- Defining the research needed for improvement;

- The specifications for the development and translation of the innovation into the forensic laboratory;

- The requirements and studies needed for validation and the procedures and processes critical to the implementation of the innovation; 
Proceedings of RI2I Symposium, NIST Gaithersburg, MD, June 19-20, NIST SP 2100-02

- Defining how the implementation of the innovation impacts and better meets the needs of the community as a whole;

- Demonstrating how the implementation of the innovation may impact the overall better use of resources in the laboratory (e.g., money, time, space, replacement of less efficient or outdated equipment) and in the community.

- What impact the failure to implement the innovation has on the community;

For innovation to occur and be implemented in the laboratories there has to be a need for new or better technologies to fill a gap in crime laboratories, and manufacturers have to recognize and address that gap. Cost-benefit analysis to identify the benefits of the innovation vs. the cost needs to be conducted. This may be a roadblock as there are competing innovations. Laboratories may be told by the vendors that they "need" the newest innovation. However, the laboratory must identify and define what it truly needs and what it can afford within the budget constraints and priorities of the local criminal justice system.

Resources/Cost-Benefit: There are resources that need to be considered when looking to implement new innovations in a laboratory including:

- What is the purchase price of the instrumentation and consumable materials?

- What are the direct costs of implementation?

- How much time will be invested to validate the new technology?

- How many people are available to perform the appropriate validations?

- What are the facility, space, and IT requirements?

- Are there any other innovations coming out soon that would be more beneficial (may not be able to afford to bring in both)?

- Are immediate and long-term support available?

Failure to consider multiple resource needs has resulted in purchased equipment and software packages sitting on the shelves of labs for years without being used because the lab cannot afford to take scientists off casework to validate the system or they did not plan adequately for the complementary materials or modifications required for implementation. Alternatively, laboratories may miss out on the next major innovation because they spent their budget on a less beneficial innovation. On the flip side, waiting for an innovation that is "around the corner" could lead to financial loss (from casework limits) if the innovation is adopted more slowly or if there is a production delay as well as a failure to meet the needs of law enforcement and the community as a whole.

National Support: A centralized resource center was proposed that:

- Specializes in evaluating a new or modified technology for efficacy of use in crime laboratories.

- Defines strengths and limitations for the technology.

- Provides robust foundational validation studies.

- Is available for implementation support at a sufficiently high-quality level to assist the laboratory in maintaining accreditation. 
- Provides validation and implementation plans and guides for each forensic science discipline.

- Provides support teams to assist in running validations and establishing laboratory protocols.

- Provides ongoing support after implementation may also be provided through this center if not available through other sources (e.g., developer).

- Assists standards development organizations with the generation of relevant standards for the new or modified technology.

- Has a goal of helping laboratories keep up to date.

- Is funded at a national or international level.

- A model similar to that described earlier in the day for Australia and New Zealand was proposed for the United States.

Communication: Researchers and lab managers need to recognize their respective laboratory needs and communicate these to the vendors of innovative technologies and start dialogues on how new innovations can be used to fill their gaps; this will promote innovations being made with end users in mind. Next, laboratories need to communicate with each other to help identify and suggest fixes for the needs of each laboratory. Discussions with vendors and among laboratories who faced similar issues may provide helpful solutions to a problem (e.g., solving a workflow issue).

Communicating terminology differences is another hurdle to overcome. Words can have different meanings for each entity in the process, and this could be a hindrance to successful implementation and use of an innovation. For example, "return on investment" (ROI) may be measured differently for a crime laboratory and a for-profit business. To a laboratory manager it may mean needing fewer instruments to maintain or the ability to run more cases simultaneously, thus freeing up more scientists for other projects. On the business end it may mean an increase in profit based on the cost of implementing the new technology or increased business and reputation for having the latest innovations.

Ongoing Vendor Support: The group identified the need for continued communications and ongoing support from vendors post-implementation of new instrumentation and technologies to ensure continued proper use and quality output. In addition, feedback and dialogue with the vendor is critical for future modifications and innovations to meet the needs of the forensic community.

\section{Summary of Breakout Sessions}

\subsection{Breakout Sessions A Summary}

In Breakout Session A, participants were grouped by their backgrounds: research, laboratory management, business, and legal. During this session, participants were asked to expand on the plenary sessions and discuss the barriers they experience in implementing new technology:

\section{Research:}


Proceedings of RI2I Symposium, NIST Gaithersburg, MD, June 19-20, NIST SP 2100-02

- Risk aversion - Traditionally laboratories are conservative and don’t like to take risks in implementing new technology

- Partnerships and collaborations - There is a lack of collaboration between researchers and forensic practitioners which hurts product development

- Validation - Validation can be a lengthy and demanding process on a laboratory

- National standards - There is no national laboratory that can provide oversight on standards and validation

- Information overload - With the amount of research that is published each year, laboratories don't have time to sift through all of it to figure out what innovations are best

- Quality systems and infrastructure - Quality systems can be strict and inhibit the adoption of new technology

\section{Laboratory:}

- Laboratory needs - New technology is often created without the input of laboratories and has too many bells and whistles

- Training and education - Laboratories have to spend a lot of time and resources getting their staff trained on new implementations

- Caseload - Caseloads often increase with the addition of new technology because of customer demand for the new technology

- Procurement - Many laboratories have strict rules to follow when it comes to procurement, and it can be a lengthy process

- Validation and standardization - Validation is a lengthy process and there are no set standards to use for validation

- Communication - There is no communication between laboratories and researchers about the limitations and IT needs of a laboratory. There is also a communication disconnect between the court system and laboratories in explaining what casework can be done

\section{Business:}

- Risk - Laboratories don't want methods that are not proven or that present more risk

- Trust - Laboratories need to trust manufacturers that their products work as advertised

- Budget - The costs for new technologies are often very high

- Priorities - There is often a disconnect between the priorities of laboratory managers working on cases and those above them, such as quality control and jurisdictional rules

\section{Legal:}

- Culture and education - Scientists need to be educated about the legal requirements for court admissibility while attorneys and other court personnel need to be educated of the scientific limitations of a test

- Proper validation - Well-conceived, robust validation studies are critical to implementation success 
- Resources and prioritization of resources - Resources need to be plentiful for laboratories, and if they are not, prioritization of the needs of the laboratory and the courts needs to be taken into consideration

- Risk aversion - All tests have inherent error rates, which concern the court system and scientists alike

- Effective communication - Successful admissibility of new technology requires effective communication

- “General acceptance” and varying procedures for courts - There is no set definition for "general acceptance," which allows for differing admissibility requirements depending on the jurisdiction

- Testing/retesting of old cases - The implementation of new technology may increase caseload due to testing on old cases that was not possible before

Figure 2 illustrates the main issues discussed by each breakout group in Session A.



Figure 2. Breakout Session A discussion points.

The one theme that was most commonly discussed throughout each of the four groups was communication. There is a gap between stakeholders. For example:

- Between researchers/businesses and laboratories, there is a lack of discussion about what type of innovations are needed in a laboratory and what will actually be purchased.

- Between laboratories/researchers and the court there is a lack of dialogue surrounding the limitations and applicability of a new technology, as well as technology limitations. 
Proceedings of RI2I Symposium, NIST Gaithersburg, MD, June 19-20, NIST SP 2100-02

Three of the groups touched upon validation and standardization, a difficult and lengthy process for busy laboratories. There is no set standard for validation, and laboratories spend time and resources with every new implementation creating validation tests, gathering results, and writing up validation studies.

Another common discussion was risk. Laboratories take risks when implementing new technologies. Often when the technology is novel, there are limited ways to determine the long-term outcomes or cost-savings. There is also the risk of general acceptance in court, where new methods are not always approved right away, and you risk losing cases until this approval comes.

After identifying issues, some of the groups naturally turned to discussing potential solutions to these barriers. Again, the groups ended up coming to similar conclusions about potential solutions.

Research: A centralized resource that can offer implementation services to forensic laboratories would be helpful. This was further discussed in the form of a centralized place, or depository, where laboratories can share their protocols and inspectors can share results.

Laboratory Management: Resource sharing would be helpful. This could take the form of a central organization that could identify trends and evaluate research, then disseminated this information to laboratories so that they could make informed decisions on new technologies. Additionally, laboratories could coordinate regionally to purchase and share equipment. This regional co-op could also be used as an opportunity for laboratories to share validation tests and results with one another. Laboratories could also take advantage of external pressures to hasten procurement of new technology. These external pressures may come from the media, prosecutors, and legislators.

Business: Vendors should provide more insight into the expected life cycle of new technology. Independent third-party validation could help laboratories lower the perception of risk and help with court acceptance. Another solution was the use of a subject matter expert or decision influencer who could perform periodic reviews of a laboratory's needs and then inform and influence product implementation to close potential gaps. If vendors could provide training and/or proficiency testing, this would take a large burden off of the laboratories, making implementation more likely. Finally, better tools and systems need to be developed for publicly funded entities to regularly measure the market demand of their service areas.

\subsection{Breakout Sessions B Summary}

In Day 2 the participants were split into four groups so that each group was comprised of a mixture of researchers, forensic science practitioners, businesses, and legal professionals.

\section{Group 1:}


Proceedings of RI2I Symposium, NIST Gaithersburg, MD, June 19-20, NIST SP 2100-02

Participants discussed the QTOF instrument and what benefits it offered compared to instruments already on the market. Some agreed the instrument has strengths over current technology, but not all were certain that it would be helpful in every laboratory.

Some barriers brought up in this session included justification, costs, and communication, and touched on other points like acceptability, standards, market size, and moral obligations. Even when discussing a separate instrument from innovation to implementation, the same barriers were realized. Collaboration, government support, and better communication would all help facilitate a smoother implementation process.

\section{Group 2:}

This group began with asking participants if they had the QTOF in their labs yet and what barriers they have had or expect in the implementation of the instrument. The barriers identified were cost-benefit, training, validation, and communication. Participants discussed whether the implementation of the QTOF would specifically benefit their laboratories (where applicable), and the majority agreed it would more likely be positive than negative. In discussing what could be done to help implement new technology more easily, the group said that existing laboratories publishing their results on time- and cost-savings, it would help their own cost-benefit analyses. Additionally, there is a need for a full-life cycle cost analysis to determine where the savings will be and how long it will take to realize them. And finally, we need better communication and education of the courts and the public on the limitations of new technologies.

\section{Group 3:}

In implementing the QTOF, the barriers identified were accreditation, vendor differences, risk, trust, cost, policy, and competition. The group agreed that laboratories need a separate, independent R\&D governance program that can help prioritize competing initiatives.

\section{Group 4:}

Discussions of general implementation issues in crime laboratories resulted in these barriers: demonstration of needs and risks, resources/cost-benefit, national support, communication, and ongoing vendor support. A centralized resource center that can evaluate new technology, define strengths and weaknesses, and provide robust validation studies would help laboratories implement new technologies much more easily.

The one theme or barrier that was discussed in all four sections of Breakout Session B was cost. The cost of not only the instrument but of implementation can be very high, which is what puts laboratories off of procuring new technology.

\section{Next Steps}

The RI2I Symposium facilitated the opportunity for dialog among researchers, forensic science practitioners, businesses, and legal professionals. The ideas discussed during the Symposium led to several potential next steps: 
- Explore the creation of a national organization (e.g., National Laboratory) that could potentially serve as a resource for all forensic laboratories preparing to implement a new technology and thereby reduce barriers and resource demands (including costs) for forensic laboratories. The organization could provide support by:

o Reviewing and evaluating new innovations so that every laboratory manager does not have to perform the same tasks individually.

o Serving as a repository for information including:

- Cost-benefit analyses

- Validation studies

- Return on investment (ROI) studies

- Standard operating procedures

- Other pertinent documents that may streamline the implementation process for a busy and often overworked laboratory

o Assessing laboratories periodically to help determine where they have gaps and recommend what new technology might be helpful.

o Developing solutions to terminology differences among researchers, operational personnel, and courts

o Supporting validation studies by providing:

- Guidance for validation studies

- Validation samples

- External review services

o Making equipment available for laboratories to evaluate

o Providing centralized training to educate stakeholders (e.g., courts on new technology, researchers and scientists on court admissibility and general acceptance, researchers on operational challenges and the need for new technology)

- Investigate ways to enhance communication between forensic stakeholders

- Investigate ways to incentivize researchers and businesses to implement technology that is helpful and tailored to forensic laboratories. This may include incentives for work with forensic practitioners to address and overcome operational challenges faced by forensic laboratories. 
Proceedings of RI2I Symposium, NIST Gaithersburg, MD, June 19-20, NIST SP 2100-02

\section{Attachment A: Agenda}

\section{Wednesday, June 19}

\begin{tabular}{|c|c|c|}
\hline $7: 30-8: 30$ & Registration and Coffee & \\
\hline $8: 30-9: 00$ & Opening Remarks & $\begin{array}{l}\text { Walt Copan } \\
\text { Director of NIST }\end{array}$ \\
\hline 9:00-10:00 & $\begin{array}{l}\text { Plenary I } \\
\text { Research Perspective }\end{array}$ & $\begin{array}{l}\text { Glen Jackson } \\
\text { West Virginia University } \\
\text { Gene Peters } \\
\text { Chief, Counterterrorism and Forensic Science } \\
\text { Research, FBI Laboratory }\end{array}$ \\
\hline $10: 00-10: 30$ & Posters and Exhibitors & \\
\hline $10: 30-11: 30$ & $\begin{array}{l}\text { Plenary II } \\
\text { Lab Management } \\
\text { Perspective }\end{array}$ & $\begin{array}{l}\text { Jenifer Smith } \\
\text { Director, Department of Forensic Sciences, } \\
\text { Washington DC } \\
\text { Edward "Chip" Pollock } \\
\text { Laboratory Director, Sacramento County DA's Office - } \\
\text { Laboratory of Forensic Services }\end{array}$ \\
\hline $11: 30-12: 30$ & $\begin{array}{l}\text { Plenary III } \\
\text { Business Perspective }\end{array}$ & $\begin{array}{l}\text { Barry Logan } \\
\text { Senior Vice President of Forensic Science Initiatives, } \\
\text { NMS Labs } \\
\text { Amy Liberty } \\
\text { Sr. Product Mgt., Thermo Fisher Scientific }\end{array}$ \\
\hline $12: 30-1: 30$ & Lunch Break & Lunch on your own \\
\hline $1: 30-2: 30$ & $\begin{array}{l}\text { Plenary IV } \\
\text { Courts Perspective }\end{array}$ & $\begin{array}{l}\text { Stephanie Domitrovich } \\
\text { Chair of Forensic Science Committee of the ABA } \\
\text { Judicial Division Dawn Boswell } \\
\text { Tarrant County Criminal District Attorney's Office, } \\
\text { Chief, Conviction Integrity Unit }\end{array}$ \\
\hline $2: 30-3: 30$ & Posters and Exhibitors & \\
\hline $3: 30-5: 00$ & Breakout Session A & $\begin{array}{l}\text { Validation and Amplification of Plenaries (see map on } \\
\text { page 2) }\end{array}$ \\
\hline 5:00-7:00 & $\begin{array}{l}\text { Reception and Posters } \\
\text { and Exhibitors }\end{array}$ & \\
\hline
\end{tabular}


Proceedings of RI2I Symposium, NIST Gaithersburg, MD, June 19-20, NIST SP 2100-02

\section{Thursday, June 20}

\begin{tabular}{|c|c|c|}
\hline $8: 30-9: 45$ & Report out on Breakout A & \\
\hline 9:45-10:15 & $\begin{array}{l}\text { Coffee, Posters, and } \\
\text { Exhibitors }\end{array}$ & \\
\hline 10:15-11:15 & $\begin{array}{l}\text { Plenary V } \\
\text { Experience, Progress, } \\
\text { and Perspective from } \\
\text { Abroad }\end{array}$ & $\begin{array}{l}\text { Robert Morgan Senior Forensic Project Officer } \\
\text { National Institute of Forensic Science Australia New } \\
\text { Zealand } \\
\text { Gillian Tully } \\
\text { UK Forensic Science Regulator }\end{array}$ \\
\hline $11: 15-11: 30$ & $\begin{array}{l}\text { Explanation of Breakout } \\
\text { B }\end{array}$ & $\begin{array}{l}\text { Summary of Topic to Be Discussed - Identification of } \\
\text { Fentanyl Isomers using non-targeted analysis with a } \\
\text { LC-QTOF in the toxicology laboratory }\end{array}$ \\
\hline 11:30-1:00 & Breakout Session B & \\
\hline 1:00-2:00 & Lunch & Lunch on your own \\
\hline $2: 00-3: 00$ & Plenary Recap & Breakout B findings and Next Steps \\
\hline $3: 00$ & Symposium Ends & \\
\hline
\end{tabular}

